\title{
Construction of 2D/0D/2D face-to-face contact g- C3N4@Au@Bi4Ti3012 heterojunction photocatalysts for promising dye degradation
}

Huajing Gao

lanzhou university of technology

Xinxin Zhao

Lanzhou University of Technology

Chunni Wang

Lanzhou University of Technology

Haimin Zhang

Lanzhou University of Technology

Jiafu Chen

Southwest University of Science and Techonolgy

Shifa Wang

Chongqing Three Gorges University

Hua Yang ( $\nabla$ hyang@lut.cn )

Lanzhou University of Technology

\section{Nano Express}

Keywords: Bi4Ti3012 nanosheets, g-C3N4 nanosheets, Au nanoparticles, g-C3N4@Au@Bi4Ti3012 heterojunctions, face-to-face contact, photodegradation performance

Posted Date: February 27th, 2020

DOI: https://doi.org/10.21203/rs.2.24740/v1

License: (a) This work is licensed under a Creative Commons Attribution 4.0 International License. Read Full License 


\section{Abstract}

Herein a new type of 2D/0D/2D face-to-face contact g-C 3 N 4 @Au@Bi 4 Ti 3012 heterojunction photocatalysts have been developed. The ternary composite photocatalysts are constructed by coupling Bi 4 Ti 3012 nanosheets with g-C 3 N 4 nanosheets face-to-face and sandwiching Au nanoparticles between Bi 4 Ti 3012 and g-C 3 N 4 nanosheets. The as-prepared g-C 3 N 4 @Au@Bi 4 Ti 3012 composite photocatalysts were systematically investigated by various characterization techniques including XRD, UV-vis DRS, FTIR, SEM, TEM and XPS. The degradation experiments were carried out by removing rhodamine $B(\mathrm{RhB})$ from water under simulated sunlight. It is found that the g-C $3 \mathrm{~N} 4$ @Au@Bi $4 \mathrm{Ti} 3012$ composite photocatalysts exhibit much enhanced photodegradation performance when compared with bare Bi $4 \mathrm{Ti} 3012$ and g-C $3 \mathrm{~N} 4$ nanosheets, and moreover they exhibit excellent photocatalytic stability in recycling dye degradation. The underlying photodegradation mechanism of the g-C 3 N 4 @Au@Bi 4 Ti 3012 composite photocatalysts was systematically investigated and discussed.

\section{Introduction}

Water, being an important element of life, is getting polluted ever increasingly due to the generation of huge amount of wastewater annually from chemical industries. Organic dyes (e.g., rhodamine B (RhB)) are majorly included in the industrial effluent, which impose a potential threat to our health and survival due to their high water solubility, chemical stability, non-biodegradability and carcinogenicity. In recent years, semiconductor-based photocatalysis has gained increasing interest in water remediation [1-4]. This technology stands out due to its capability of utilizing solar radiation to decompose the harmful organic dyes. The sunlight-induced conduction band (CB) electrons $\left(\mathrm{e}^{-}\right)$and valence band (VB) holes $\left(\mathrm{h}^{+}\right)$ in photocatalysts possess the reduction/oxidation capabilities are the basic reactive species, which take part in the direct or indirect redox reactions to cause the dye decomposition. Nevertheless, the photodegradation activities of most semiconductor photocatalysts are limited due to the easy recombination of photoexcited $\mathrm{e}^{-} / \mathrm{h}^{+}$pairs. Efficient suppression of the photoexcited electron/hole recombination has become one of most important strategies to improve the photodegradation performances of semiconductors [5-11].

Noble metal and carbon nanomaterials, attracting extensive attention owing to their outstanding physical properties and broad application prospects [12-20], have been extensively employed to modify the photocatalysts in order to improve their photodegradation performances [21-26]. The main enhanced photocatalytic mechanism is that these nanomaterials can serve as good electron sinks to trap the photoproduced electrons, thus leading to the decreased combination of $\mathrm{e}^{-} / \mathrm{h}^{+}$pairs. Furthermore, these nanomaterials can efficiently absorb and utilize visible light during the photocatalytic process benefiting from the photoluminescence up-conversion of carbon nanomaterials and localized surface plasmon resonance (LSPR) of noble metal nanoparticles [27-29]. Construction of semiconductor-semiconductor heterojunctions is another important avenue showing the capability to separate the photoexcited $\mathrm{e}^{-} / \mathrm{h}^{+}$ pairs [30-34]. The photoproduced carriers will transfer one semiconductor to another under the action of 
the formed internal electric field at the heterojunction interface, thus resulting in the efficient $\mathrm{e}^{-} / \mathrm{h}^{+}$ separation. How to optimize the interface and realize good contact between two semiconductors is the key point facilitate the carrier transfer and separation.

Bismuth titanate $\left(\mathrm{Bi}_{4} \mathrm{Ti}_{3} \mathrm{O}_{12}, \mathrm{BTO}\right)$ with bandgap energy of $\sim 3.1 \mathrm{eV}$ [35], crystallizing in a layer structure constructed by an alternating stack of perovskite-like $\left(\mathrm{Bi}_{2} \mathrm{Ti}_{3} \mathrm{O}_{10}\right)^{2-}$ blocks and $\left(\mathrm{Bi}_{2} \mathrm{O}_{2}\right)^{2+}$ units, has received much recent attention as an important semiconductor photocatalyst for photodegradation of organic pollutants [36-41]. Due to its special layer structure, $\mathrm{Bi}_{4} \mathrm{Ti}_{3} \mathrm{O}_{12}$ exhibits a high anisotropy of photocatalytic properties. In particular, the (010) facet is expected to have a high photocatalytic activity because the photoproduced electrons and hole are readily separated and migrate to the (010) facet driving by the polarization electric field (along the [010] direction) [42]. This was confirmed by the observation of extremely high photodegradation activity of two-dimensional (2D) $\mathrm{Bi}_{4} \mathrm{Ti}_{3} \mathrm{O}_{12}$ nanosheets with nearly $100 \%$ exposed (010) facet [35]. Graphite-like carbon nitride $\left(\mathrm{g}-\mathrm{C}_{3} \mathrm{~N}_{4}, \mathrm{CN}\right)$ is famously known to be a metal-free polymeric semiconductor, showing a promising visible-light-responsive photoactivity [38]. Due to its simple preparation and excellent thermal/chemical stability, $g-C_{3} N_{4}$ is interesting for the application in organic dye photodegradation. Moreover, $\mathrm{g}-\mathrm{C}_{3} \mathrm{~N}_{4}$ is bonded with abundant surface groups, implying that it is suitable for hybridizing with other photocatalyststs to form heterojunctions [43-47].

Herein g- $\mathrm{C}_{3} \mathrm{~N}_{4}$ and $\mathrm{Bi}_{4} \mathrm{Ti}_{3} \mathrm{O}_{12}$ nanosheets have been coupled together face-to-face via a hydrothermal route. The derived 2D/2D g- $\mathrm{C}_{3} \mathrm{~N}_{4} @ \mathrm{Bi}_{4} \mathrm{Ti}_{3} \mathrm{O}_{12}$ heterojunctions have a maximum contact area and are beneficial to the carrier transfer and separation. Furthermore, zero-dimensional (OD) Au nanoparticles have been sandwiched between $\mathrm{g}-\mathrm{C}_{3} \mathrm{~N}_{4}$ and $\mathrm{Bi}_{4} \mathrm{Ti}_{3} \mathrm{O}_{12}$ nanosheets to construct $2 \mathrm{D} / 0 \mathrm{D} / 2 \mathrm{D} \mathrm{g}$ $\mathrm{C}_{3} \mathrm{~N}_{4} @ \mathrm{Au} @ \mathrm{Bi}_{4} \mathrm{Ti}_{3} \mathrm{O}_{12}$ heterojunctions, where Au nanoparticles serve as the conductive bridges to facilitate the charge transfer between $\mathrm{g}-\mathrm{C}_{3} \mathrm{~N}_{4}$ and $\mathrm{Bi}_{4} \mathrm{Ti}_{3} \mathrm{O}_{12}$. RhB was used as the model dye to evaluate the photocatalysis degradation performances of the as-prepared g- $\mathrm{C}_{3} \mathrm{~N}_{4} @ A u @ \mathrm{Bi}_{4} \mathrm{Ti}_{3} \mathrm{O}_{12}$ composite photocatalysts under irradiation of simulated sunlight. It is demonstrated that the photodecomposition performances of composite photocatalysts are much higher than those of bare $\mathrm{g}-\mathrm{C}_{3} \mathrm{~N}_{4}$ and $\mathrm{Bi}_{4} \mathrm{Ti}_{3} \mathrm{O}_{12}$ nanosheets.

\section{Experimental}

\subsection{Synthesis of $\mathrm{g}-\mathrm{C}_{3} \mathrm{~N}_{4}$ and $\mathrm{Bi}_{4} \mathrm{Ti}_{3} \mathrm{O}_{12}$ nanosheets}

All chemical reagents (analytical grade) used in the present experiments were directly supplied by chemical industries without further purification. A simple pyrolysis of melamine was used to fabricate g$\mathrm{C}_{3} \mathrm{~N}_{4}$ nanosheets. Typically, $5 \mathrm{~g}$ of melamine was put in a corundum boat, semi-closed with a cover, and then calcinated in a tube furnace $\left(520^{\circ} \mathrm{C}, 4 \mathrm{~h}\right)$. The calcinated product was ground and obtained as final $\mathrm{g}-\mathrm{C}_{3} \mathrm{~N}_{4}$ nanosheets. 
A hydrothermal method as elaborated in the literature was employed to synthesize $\mathrm{Bi}_{4} \mathrm{Ti}_{3} \mathrm{O}_{12}$ nanosheets [35]. A stoichiometric amount of bismuth nitrate pentahydrate $\left(\mathrm{Bi}\left(\mathrm{NO}_{3}\right)_{3} \cdot 5 \mathrm{H}_{2} \mathrm{O}, 1.9402 \mathrm{~g}\right)$ was dissolved in $10 \%(\mathrm{v} / \mathrm{v})$ dilute nitric acid solution. To the $\mathrm{Bi}\left(\mathrm{NO}_{3}\right)_{3}$ solution was then slowly added with titanium tetrachloride solution $\left(0.5691 \mathrm{~g} \mathrm{TiCl}_{4}+20 \mathrm{~mL}\right.$ deionized water) and sodium hydroxide solution $(4.8 \mathrm{~g}$ $\mathrm{NaOH}+40 \mathrm{~mL}$ deionized water). The resultant mixture was loaded into a Teflon-lined autoclave and subjected to the hydrothermal reaction at $200{ }^{\circ} \mathrm{C}$ for $24 \mathrm{~h}$. After that, the precipitate was gathered as $\mathrm{Bi}_{4} \mathrm{Ti}_{3} \mathrm{O}_{12}$ nanosheets, which were washed with deionized water/absolute ethanol and drying at $60^{\circ} \mathrm{C}$ for $12 \mathrm{~h}$.

\subsection{Fabrication of CN@BTO composites}

During the above hydrothermal preparation process of $\mathrm{Bi}_{4} \mathrm{Ti}_{3} \mathrm{O}_{12}$ nanosheets, stoichiometric $\mathrm{g}-\mathrm{C}_{3} \mathrm{~N}_{4}$ nanosheets were uniformly dispersed in the precursor mixture solution, which results in the preparation of CN@BTO composites. The hydrothermal reaction temperature/time and sample collection/washing/drying process were performed under the same conditions. By adding different amounts of $\mathrm{g}-\mathrm{C}_{3} \mathrm{~N}_{4}$ nanosheets in the precursor mixture solution, several CN@BTO composite samples with different $\mathrm{g}-\mathrm{C}_{3} \mathrm{~N}_{4}$ mass fractions were prepared (i.e., 5\%CN@BT0, 10\%CN@BT0 and 15\%CN@BT0).

\subsection{Fabrication of CN@Au@BTO composites}

The CN@Au@BTO composites were prepared using the following two processes. The first process was to decorate Au nanoparticles on the surface of $\mathrm{g}-\mathrm{C}_{3} \mathrm{~N}_{4}$ nanosheets via a photocatalytic reduction route. Stoichiometric ammonium oxalate $(\mathrm{AO}, 0.025 \mathrm{~g})$ and $\mathrm{g}-\mathrm{C}_{3} \mathrm{~N}_{4}$ nanosheets $(0.13 \mathrm{~g})$ were put in deionized water $(80 \mathrm{~mL})$, followed by ultrasonic dispersion $(30 \mathrm{~min})$ and magnetic stirring $(1 \mathrm{~h})$. Subsequently, $\mathrm{HAuCl}_{4}$ aqueous solution $\left(0.029 \mathrm{~mol} \mathrm{~L}^{-1}, 1 \mathrm{~mL}\right)$ was added to the above suspension, and then irradiated by a $15 \mathrm{~W}$ low-pressure mercury lamp for $30 \mathrm{~min}$. The product, i.e. CN@Au composite, was rinsed with deionized water/absolute ethanol and subjected to drying at $60^{\circ} \mathrm{C}$ for $12 \mathrm{~h}$. In the second step, the asprepared CN@Au composite was loaded in the precursor mixture solution that was used for the preparation of $\mathrm{Bi}_{4} \mathrm{Ti}_{3} \mathrm{O}_{12}$ nanosheets as described in 2.1 section. The subsequent hydrothermal treatment process followed the same procedure for the $\mathrm{Bi}_{4} \mathrm{Ti}_{3} \mathrm{O}_{12}$ preparation. The composite derived according to this procedure was designated as $10 \% \mathrm{CN} @ 4.2 \% \mathrm{Au} @ \mathrm{BTO}$, where $\mathrm{g}-\mathrm{C}_{3} \mathrm{~N}_{4}$ and $\mathrm{Au}$ occupy a mass fraction of $\sim 10 \%$ and $\sim 4.2 \%$, respectively. Figure 1 depicts the preparation process of $\mathrm{CN} @ B T 0$ and CN@Au@BTO composite photocatalysts.

\subsection{Sample characterization methods}

X-ray powder diffraction (XRD) measurements were carried out by using a D8 Advance X-ray diffractometer $\left(\lambda_{\mathrm{Cu}-\mathrm{ka}}=0.15406 \mathrm{~nm}\right)$. A TU-1901 double beam spectrophotometer was applied for the analysis of ultraviolet-visible diffuse reflectance spectroscopy (UV-vis DRS). Fourier transform infrared (FTIR) spectra were collected on a Spectrum Two FTIR spectrophotometer. A JSM-6701F field-emission scanning electron microscope was employed for the scanning electron microscopy (SEM) observations. 
Transmission electron microscopy (TEM) investigations were carried out by means of a JEM-1200EX field-emission transmission electron microscope. X-ray photoelectron spectroscopy (XPS) was recorded on a PHI-5702 multi-functional X-ray photoelectron spectrometer.

\subsection{Photocatalytic testing process}

Simulated-sunlight driven photodecomposition of RhB was used to evaluate the photoactivities of the asprepared photocatalysts. The initial RhB concentration was $\mathrm{C}_{0}=5 \mathrm{mg} \mathrm{L}^{-1}$ and the photocatalyst dosage was $C_{\text {photocatalyst }}=1000 \mathrm{mg} \mathrm{L}^{-1}$. The photoreactor (capacity: $200 \mathrm{~mL}$ ) was filled with $100 \mathrm{~mL}$ of $\mathrm{RhB}$ solution together with $100 \mathrm{mg}$ of the photocatalyst. The adsorption experiment was performed by placing the photoreactor in the dark for $30 \mathrm{~min}$, during which a magnetic stirring was applied. After that, turn on the light (a 200-W xenon lamp emitting simulated sunlight) to start the photocatalytic experiment. The change of the RhB concentration during the photocatalysis was determined by testing its absorbance at $\lambda_{\mathrm{RhB}}=554 \mathrm{~nm}$ by using a UV-vis spectrophotometer. The photocatalyst was removed from the reaction solution by centrifugation testing the absorbance of the reaction solution. According to the initial concentration $\left(C_{0}\right)$ and residual concentration $\left(C_{t}\right)$ of $R h B$, the degradation percentage $(\eta)$ of $R h B$ was derived as: $\eta=\left(C_{0}-C_{t}\right) / C_{0} \times 100 \%$.

\section{Results And Discussion}

XRD patterns of g- $\mathrm{C}_{3} \mathrm{~N}_{4}, \mathrm{Bi}_{4} \mathrm{Ti}_{3} \mathrm{O}_{12}$ and 10\%CN@4.2\%Au@BTO were recorded to determine their crystalline structures, as displayed in Fig. 2. On the XRD pattern of $\mathrm{g}-\mathrm{C}_{3} \mathrm{~N}_{4}$, two diffraction peaks are observed at $13.17^{\circ}$ and $27.40^{\circ}$, which correspond to the in-plane structural packing motif of tri-s-triazine units (i.e., (100) facet) and the inter-layer stacking of conjugated aromatic system (i.e., (002) facet), respectively [47]. This diffraction feature suggests that $\mathrm{g}-\mathrm{C}_{3} \mathrm{~N}_{4}$ nanosheets are obtained. The diffraction peaks of $\mathrm{Bi}_{4} \mathrm{Ti}_{3} \mathrm{O}_{12}$, matching well with the diffraction data of PDF\#35-0795, imply the formation of pure $\mathrm{Bi}_{4} \mathrm{Ti}_{3} \mathrm{O}_{12}$ orthorhombic phase (cell: $0.545 \times 3.282 \times 0.541 \mathrm{~nm}^{3}$ ). The XRD pattern of $10 \% \mathrm{CN} @ 4.2 \% \mathrm{Au} @ \mathrm{BTO}$ is very similar to that of bare $\mathrm{Bi}_{4} \mathrm{Ti}_{3} \mathrm{O}_{12}$, indicating no structural change of the orthorhombic $\mathrm{Bi}_{4} \mathrm{Ti}_{3} \mathrm{O}_{12}$ in the composite. The XRD pattern of the composite presents no diffraction peaks assignable to $\mathrm{g}-\mathrm{C}_{3} \mathrm{~N}_{4}$ nanosheets and Au nanoparticles, which is possibly due to the low diffraction intensities of $\mathrm{g}-\mathrm{C}_{3} \mathrm{~N}_{4}$ and low content of $\mathrm{Au}$.

It is necessary to characterize the light-absorption characteristics of nanomaterials because they are highly related to their physical properties [48-50]. UV-vis DRS measurements were carried out to determine the optical absorption properties of $\mathrm{Bi}_{4} \mathrm{Ti}_{3} \mathrm{O}_{12}, \mathrm{~g}-\mathrm{C}_{3} \mathrm{~N}_{4}, 10 \% \mathrm{CN} @ \mathrm{BTO}$ and 10\%CN@4.2\%Au@BTO. As shown in Fig. 3(a), $\mathrm{Bi}_{4} \mathrm{Ti}_{3} \mathrm{O}_{12}, \mathrm{~g}-\mathrm{C}_{3} \mathrm{~N}_{4}$ and 10\%CN@BTO have a poor visiblelight absorption in the wavelength region $\lambda>450 \mathrm{~nm}$. In contrast, the 10\%CN@4.2\%Au@BTO composite with the introduction of Au nanoparticles manifests a relatively higher visible-light absorption, which is attributed to the strong light absorption of Au nanoparticles in the visible-light region. The absorption peak observed at around 550 nm for the 10\%CN@4.2\%Au@BTO composite can be characterized as the 
plasmon resonance peak of Au nanoparticles [35]. Figure 3(c) shows the apparent colors of the samples, further confirming their visible-light absorption properties. It is observed that $\mathrm{Bi}_{4} \mathrm{Ti}_{3} \mathrm{O}_{12}, \mathrm{~g}^{-} \mathrm{C}_{3} \mathrm{~N}_{4}$ and $10 \% \mathrm{CN} @ B$ BT present a white or faint yellow color, implying a weak visible-light absorption of these samples. In contrast, a gray color is observed for 10\%CN@4.2\%Au@BTO, suggesting a relatively stronger visible-light absorption of the ternary composite photocatalyst. Figure 3(b) depicts the differential curves of UV-vis DRS spectra, from which the wavelength of absorption edge $\left(\lambda_{\text {abs }}\right)$ can be derived [51]). The bandgap of bare $\mathrm{Bi}_{4} \mathrm{Ti}_{3} \mathrm{O}_{12}$ and $\mathrm{g}-\mathrm{C}_{3} \mathrm{~N}_{4}$ is obtained as 3.13 and $2.83 \mathrm{eV}$, respectively. For the $10 \% \mathrm{CN} @ \mathrm{BTO}$ and 10\%CN@4.2\%Au@BTO composites, the bandgap of $\mathrm{Bi}_{4} \mathrm{Ti}_{3} \mathrm{O}_{12}$ and $\mathrm{g}-\mathrm{C}_{3} \mathrm{~N}_{4}$ undergoes a slight change possibly due to their interactions.

FTIR analysis was employed to reveal the possible presence of functional groups in the samples, as illustrated in Fig. 4. Figure 4(a) presents the FTIR spectrum of $\mathrm{Bi}_{4} \mathrm{Ti}_{3} \mathrm{O}_{12}$, where the absorption peaks located at 571 and $472 \mathrm{~cm}^{-1}$ originate from the stretching vibration of Ti-0, and the peak at $825 \mathrm{~cm}^{-1}$ is ascribed to the $\mathrm{Bi}-\mathrm{O}$ stretching vibration, which confirms the crystallization of $\mathrm{Bi}_{4} \mathrm{Ti}_{3} \mathrm{O}_{12}$ structure [35]. The peaks at 1096 and $1403 \mathrm{~cm}^{-1}$ could originate from the symmetric and anti-symmetric stretching vibrations of $\mathrm{CO}_{3}{ }^{2-}$ groups introduced on the surface of $\mathrm{Bi}_{4} \mathrm{Ti}_{3} \mathrm{O}_{12}$ during the hydrothermal synthesis process, respectively [52]. The absorption peak located at $1642 \mathrm{~cm}^{-1}$ is induced by the $\mathrm{H}-\mathrm{O}$ bending vibration of water molecules [53]. On the FTIR spectrum of $\mathrm{g}-\mathrm{C}_{3} \mathrm{~N}_{4}$ (Fig. 4(b)), the characteristic absorption peaks of g- $\mathrm{C}_{3} \mathrm{~N}_{4}$ nanosheets are observed at $807 \mathrm{~cm}^{-1}$ (breathing mode of the tri-s-triazine units), $1247 / 1324 \mathrm{~cm}^{-1}$ (stretching vibrations of $\mathrm{C}-\mathrm{NH}-\mathrm{C}$ bridges), and $1410-1640 \mathrm{~cm}^{-1}$ (C-N heterocycles skeletal vibrations of aromatic rings) [47]. For the 10\%CN@BTO and 10\%CN@4.2\%Au@BTO composites, the absorption peaks of $\mathrm{Bi}_{4} \mathrm{Ti}_{3} \mathrm{O}_{12}$ and g- $\mathrm{C}_{3} \mathrm{~N}_{4}$ are detected on their FTIR spectra (Fig. 4(c) and (d)), indicating that $\mathrm{Bi}_{4} \mathrm{Ti}_{3} \mathrm{O}_{12}$ and g- $\mathrm{C}_{3} \mathrm{~N}_{4}$ are included in the composites without structural change. No characteristic peaks from Au nanoparticles are detected for 10\%CN@4.2\%Au@BTO possible due to infrared inactivity of Au nanoparticles. For all the samples, the presence of $\mathrm{CO}_{3}{ }^{2-}$ groups and water molecules on their surface is confirmed by the observation of the infrared-absorption peaks 1403 and $1642 \mathrm{~cm}^{-1}$.

SEM observation was carried out to reveal the morphologies of $\mathrm{Bi}_{4} \mathrm{Ti}_{3} \mathrm{O}_{12}$ and 10\%CN@4.2\%Au@BTO. Figure 5(a) shows the SEM image of $\mathrm{Bi}_{4} \mathrm{Ti}_{3} \mathrm{O}_{12}$, implying that $\mathrm{Bi}_{4} \mathrm{Ti}_{3} \mathrm{O}_{12}$ is crystallized into nanosheets with thickness of $45-80 \mathrm{~nm}$ (average thickness: $\sim 60 \mathrm{~nm}$ ). The surface of $\mathrm{Bi}_{4} \mathrm{Ti}_{3} \mathrm{O}_{12}$ nanosheets appears smooth and clean. Figure 5(b) shows the SEM image of 10\%CN@4.2\%Au@BTO, demonstrating the formation of composite nanosheets with thickness of 150-210 nm (average thickness: $170 \mathrm{~nm}$ ). Compared to that of bare $\mathrm{Bi}_{4} \mathrm{Ti}_{3} \mathrm{O}_{12}$ nanosheets, the thickness of the composite nanosheets becomes much increased, suggesting that they are constructed by g- $\mathrm{C}_{3} \mathrm{~N}_{4}$ and $\mathrm{Bi}_{4} \mathrm{Ti}_{3} \mathrm{O}_{12}$ nanosheets with face-toface contact. Moreover, the surface of the composite nanosheets becomes rough possibly due to the decoration of Au nanoparticles. 
To reveal the microstructure of the 10\%CN@4.2\%Au@BTO composite, TEM investigation was further performed. Figure 6(a) and (b) show the TEM images of the composite, demonstrating that $\mathrm{g}-\mathrm{C}_{3} \mathrm{~N}_{4}$ nanosheets and $\mathrm{Bi}_{4} \mathrm{Ti}_{3} \mathrm{O}_{12}$ nanosheets are coupled face-to-face and $\mathrm{Au}$ nanoparticles are possibly sandwiched between $\mathrm{g}-\mathrm{C}_{3} \mathrm{~N}_{4}$ and $\mathrm{Bi}_{4} \mathrm{Ti}_{3} \mathrm{O}_{12}$ nanosheets. On the selected area electron diffraction (SAED) pattern (Fig. $6(\mathrm{C})$ ), one can see that the diffraction spots are periodically arranged and can be indexed into the [010] zone axis of $\mathrm{Bi}_{4} \mathrm{Ti}_{3} \mathrm{O}_{12}$ orthorhombic phase. This implies that $\mathrm{Bi}_{4} \mathrm{Ti}_{3} \mathrm{O}_{12}$ nanosheets are featured by a single-crystalline nature with highly exposed (010) facet. No diffraction spots or rings from g- $\mathrm{C}_{3} \mathrm{~N}_{4}$ nanosheets and Au nanoparticles are detected on the SAED pattern, which is possibly due to the amorphous feature of $\mathrm{g}-\mathrm{C}_{3} \mathrm{~N}_{4}$ nanosheets and absence of Au nanoparticles in the selected area. Figure 6(d) and (e) illustrate the high-resolution TEM (HRTEM) images of the composite, further elucidating the construction of 2D-g- $\mathrm{C}_{3} \mathrm{~N}_{4} @ 0 \mathrm{D}-\mathrm{Au} @ 2 \mathrm{D}-\mathrm{Bi}_{4} \mathrm{Ti}_{3} \mathrm{O}_{12}$ heterojunctions with face-to-face contact. The clear lattice fringes with $2 d=0.384 \mathrm{~nm}$, corresponding to the (202) facet of the orthorhombic $\mathrm{Bi}_{4} \mathrm{Ti}_{3} \mathrm{O}_{12}$, confirm the single-crystalline nature of $\mathrm{Bi}_{4} \mathrm{Ti}_{3} \mathrm{O}_{12}$ nanosheets with highly exposed (010) facet.

Energy-dispersive X-ray spectroscopy (EDS) spectrum was collected from the 10\%CN@4.2\%Au@BTO composite (Fig. 7(a)), which clearly shows the inclusion of C/N/O/Bi/Ti/O/Au species in the composite. Except for the Cu signals, possibly induced by the TEM microgrid holder [54], no other impurity elements are detected on the EDS spectrum. Figure 7(b) displays the dark-field scanning TEM (DF-STEM) image recorded from 10\%CN@4.2\%Au@BTO, and the corresponding EDS elemental mapping images of the area are presented in Fig. 7(c) $-(\mathrm{h})$. It is obvious that the composite nanosheets manifest the uniform distribution of the $\mathrm{C} / \mathrm{N} / \mathrm{O} / \mathrm{Bi} / \mathrm{Ti} / \mathrm{O}$ elements, whereas Au element is dispersedly decorated on the composite nanosheets. The elemental mapping analysis gives support to the construction of $2 \mathrm{D} / 0 \mathrm{D} / 2 \mathrm{D}$ face-to-face contact g- $\mathrm{C}_{3} \mathrm{~N}_{4} @ \mathrm{Au} @ \mathrm{Bi}_{4} \mathrm{Ti}_{3} \mathrm{O}_{12}$ heterojunctions.

The 10\%CN@4.2\%Au@BTO composite was analyzed by XPS to reveal the chemical states of the elements $\mathrm{Bi}, \mathrm{Ti}, \mathrm{O}, \mathrm{C}, \mathrm{N}$ and $\mathrm{Au}$ in the composite, as shown in Fig. 8. Two peaks separately with binding energies of $159.1\left(\mathrm{Bi}^{-4 \mathrm{f}_{7 / 2}}\right)$ and $164.4 \mathrm{eV}\left(\mathrm{Bi}-4 \mathrm{f}_{5 / 2}\right)$ are detected from the XPS spectrum of Bi-4f core level (Fig. 8(a)), implying the presence of $\mathrm{Bi}^{3+}$ oxidation state $[35,55]$. By deconvoluting the Ti-2p XPS corelevel spectrum (Fig. 8(b)), three peaks at $458.1,463.6$ and $466.0 \mathrm{eV}$ are recognized. The former two peaks correspond to the binding energies of $\mathrm{Ti}^{4+}-2 \mathrm{p}_{3 / 2}$ and $\mathrm{Ti}^{4+}-2 \mathrm{p}_{1 / 2}$, respectively, whereas the third peak can be ascribed to $B i-4 d_{3 / 2}$ binding energy $[35,56]$. The 0-1 s XPS spectrum (Fig. 8(c)) reveals two kinds of oxygen species, i.e., the crystal lattice oxygen of $\mathrm{Bi}_{4} \mathrm{Ti}_{3} \mathrm{O}_{12}(529.9 \mathrm{eV})$ and chemisorbed oxygen species on the sample $(531.9 \mathrm{eV})[35,57,58]$. The C-1 s XPS spectrum (Fig. 8(d)) presents three peaks located at $284.8,288.0$ and $282.6 \mathrm{eV}$, which are characterized as the carbon existing in the instrument, $\mathrm{sp}^{2}$ hybridized carbon in $\mathrm{g}-\mathrm{C}_{3} \mathrm{~N}_{4}$, and metal carbides, respectively [47]. On the $\mathrm{N}-1 \mathrm{~s}$ XPS spectrum (Fig. 8(e)), the binding energy peak at $397.5 \mathrm{eV}$ is ascribed to $\mathrm{sp}^{2}$-hybridized nitrogen $(\mathrm{C}=\mathrm{N}-\mathrm{C})$ resulting from $\mathrm{g}$ $\mathrm{C}_{3} \mathrm{~N}_{4}$ [47]. The strong peak at $392.2 \mathrm{eV}$ could be ascribed to the formation of metal nitrides. The observed binding energies at $84.1\left(\mathrm{Au}-4 \mathrm{f}_{7 / 2}\right)$ and $87.8 \mathrm{eV}\left(\mathrm{Au}-4 \mathrm{f}_{5 / 2}\right)$ on the Au-4f XPS spectrum (Fig. 8(f)) are indicative of the existence of metallic Au nanoparticles in the composite [35]. 
Figure 9(a) shows the time-dependent degradation curves of RhB photocatalyzed by $\mathrm{Bi}_{4} \mathrm{Ti}_{3} \mathrm{O}_{12}, \mathrm{~g}-\mathrm{C}_{3} \mathrm{~N}_{4}$, CN@BTO composites and 10\%CN@4.2\%Au@BTO composite. Before photocatalysis, the dye adsorption onto the samples is determined to be $5.4 \%-9.9 \%$. The blank (photolysis) experiment shows that RhB exhibits good stability under simulated sunlight irradiation in the absence of photocatalysts [59]. Under irradiation for $120 \mathrm{~min}$, bare $\mathrm{Bi}_{4} \mathrm{Ti}_{3} \mathrm{O}_{12}$ and g- $\mathrm{C}_{3} \mathrm{~N}_{4}$ photocatalyze $71.0 \%$ and $44.8 \%$ degradation of $\mathrm{RhB}$, respectively. When $\mathrm{Bi}_{4} \mathrm{Ti}_{3} \mathrm{O}_{12}$ nanosheets and g- $\mathrm{C}_{3} \mathrm{~N}_{4}$ nanosheets are coupled face-to-face together, the constructed CN@BTO composite nanosheets exhibit improved photodecomposition performances. The $10 \% \mathrm{CN} @ \mathrm{BTO}$ composite with a g- $\mathrm{C}_{3} \mathrm{~N}_{4}$ mass fraction of $10 \%$ is demonstrated to be the optimal composite photocatalyst, over which the degradation percentage of $\mathrm{RhB}$ reaches $85.3 \%$ after 120 min photoreaction. Furthermore, by sandwiching Au nanoparticles between $\mathrm{Bi}_{4} \mathrm{Ti}_{3} \mathrm{O}_{12}$ and g- $\mathrm{C}_{3} \mathrm{~N}_{4}$ nanosheets, a more promising ternary 10\%CN@4.2\%Au@BTO composite photocatalyst is achieved, which causes $94.4 \%$ of RhB to be photodegraded. As organic dyes are generally "tricky" in their photocatalytic degradation process, the exact photodegradation mechanism needs to be further investigated [60].

The photodegradation performances of the samples are further elucidated from the kinetic viewpoint. As displayed in Fig. 9(b), the degradation kinetic plots of RhB conform perfectly to the pseudo-first-order kinetic equation $\operatorname{Ln}\left(C_{t} / C_{0}\right)=-k_{a p p} t[61]$ due to their good linear behavior with $R^{2}$ larger than 0.99 . The apparent first-order reaction rate constant $k_{a p p}$ can be employed for the quantitative comparison between the photodegradation performances of the photocatalysts. According to the values of $\mathrm{k}_{\mathrm{app}}$ as displayed in Fig. 9(b), it is concluded that the 10\%CN@BTO composite possesses a photodegradation activity 1.8 and $\sim 3.9$ times over that of bare $\mathrm{Bi}_{4} \mathrm{Ti}_{3} \mathrm{O}_{12}$ and g-C $\mathrm{C}_{3} \mathrm{~N}_{4}$, respectively; whereas the photodegradation activity of the ternary 10\%CN@4.2\%Au@BTO is increased by 2.3 and 5.0 times compared with that of bare $\mathrm{Bi}_{4} \mathrm{Ti}_{3} \mathrm{O}_{12}$ and $\mathrm{g}-\mathrm{C}_{3} \mathrm{~N}_{4}$, respectively.

To examine the reusability of 10\%CN@4.2\%Au@BTO for photocatalytic degradation of RhB, the photocatalyst was collected by centrifugation after the photodegradation experiment and recovered with deionized water rinsing. The next photodegradation experiment was carried out under the same procedure by loading the recovered 10\%CN@4.2\%Au@BTO in fresh RhB solution. To balance the minor loss of the photocatalyst after each run, fresh photocatalyst was added. As seen in Fig. 9(c), the photodegradation percentage of RhB within 120 min reaction slightly decreases from $94.4 \%$ at the 1 st cycle to $90.1 \%$ at the 4 th cycle, implying the degradation percentage of RhB undergoes only a minor loss (3.3\%). The recycling photocatalytic experiment clearly demonstrates an excellent stability of the 10\%CN@4.2\%Au@BTO composite photocatalyst for repeatedly degrading organic dyes.

In the 10\%CN@4.2\%Au@BTO photodegradation system, the active species including hydroxyl $(\cdot \mathrm{OH})$ radicals, superoxide $\left(\cdot \mathrm{O}_{2}^{-}\right)$radicals and photoexcited holes were determined by active species trapping experiments as described in the literature [62]. Ethanol (scavenger for $\cdot \mathrm{OH}, 5 \mathrm{~mL}$ ), benzoquinone (BQ, scavenger for $\mathrm{O}_{2}{ }^{-}, 0.1 \mathrm{mmol}$ ) and ammonium oxalate ( $\mathrm{AO}$, scavenger for $\mathrm{h}^{+}, 0.1 \mathrm{mmol}$ ) were separately added in the photoreaction solution to examine their effects on the RhB degradation. As shown in Fig. 9(d), the addition of ethanol has a minor effect on the photodegradation of RhB, suggesting a very 
small role of $\cdot \mathrm{OH}$ in the photodegradation process. The dye degradation is obviously inhibited by the introduction of $\mathrm{BQ}$ or $\mathrm{AO}$, confirming that $\mathrm{O}_{2}{ }^{-}$and $\mathrm{h}^{+}$are the main reactive species causing the dye degradation. In particular, the photoexcited $\mathrm{h}^{+}$plays the largest role in the photocatalysis due to the highest suppression efficiency by AO. To quantitatively determine the role of the reactive species in the photodegradation process, the trapping experiments using more quenchers are necessary [63].

It is noted that $\mathrm{Bi}_{4} \mathrm{Ti}_{3} \mathrm{O}_{12}$ is an intrinsic n-type semiconductor $\left(\mathrm{E}_{\mathrm{g}}=3.13 \mathrm{eV}\right)$ and $\mathrm{g}-\mathrm{C}_{3} \mathrm{~N}_{4}$ behaves as an intrinsic $p$-type semiconductor $\left(E_{g}=2.83 \mathrm{eV}\right)$ [35]. The CB/VB potentials of $\mathrm{Bi}_{4} \mathrm{Ti}_{3} \mathrm{O}_{12}$ and $\mathrm{g}-\mathrm{C}_{3} \mathrm{~N}_{4}$ are theoretically estimated, by using the method elaborated in the literature $[64,65]$, to be $-0.19 /+2.94$ and $1.19 /+1.64 \mathrm{~V}$ vs NHE (normal hydrogen electrode), respectively, as schematically depicted in Fig. 10. When $\mathrm{Bi}_{4} \mathrm{Ti}_{3} \mathrm{O}_{12}$ nanosheets, Au nanoparticles and g- $\mathrm{C}_{3} \mathrm{~N}_{4}$ nanosheets are coupled to form 2D/0D/2D face-to-face contact CN@Au@BTO heterojunctions, electrons will diffuse from n-type $\mathrm{Bi}_{4} \mathrm{Ti}_{3} \mathrm{O}_{12}$ to p-type g- $\mathrm{C}_{3} \mathrm{~N}_{4}$, and conversely, holes will diffuse from p-type g- $\mathrm{C}_{3} \mathrm{~N}_{4}$ to n-type $\mathrm{Bi}_{4} \mathrm{Ti}_{3} \mathrm{O}_{12}$. The role of $\mathrm{Au}$ nanoparticles sandwiched between $\mathrm{Bi}_{4} \mathrm{Ti}_{3} \mathrm{O}_{12}$ and g- $\mathrm{C}_{3} \mathrm{~N}_{4}$ nanosheets is to act as the "bridge" to facilitate the transfer of photoexcited carriers. This carrier diffusion process leads to the creation of negative charge centers at the $\mathrm{g}-\mathrm{C}_{3} \mathrm{~N}_{4}$ interface and positive charge centers at the $\mathrm{Bi}_{4} \mathrm{Ti}_{3} \mathrm{O}_{12}$ interface, and simultaneous formation of internal electric field (pointing from $\mathrm{Bi}_{4} \mathrm{Ti}_{3} \mathrm{O}_{12}$ to $\mathrm{g}-\mathrm{C}_{3} \mathrm{~N}_{4}$ ). The created internal electric field will prevent the continuous diffusion of the charge carriers, and finally a thermal equilibrium state is reached in the CN@Au@BTO heterojunctions. Under irradiated from simulated sunlight, both $\mathrm{Bi}_{4} \mathrm{Ti}_{3} \mathrm{O}_{12}$ and $\mathrm{g}-\mathrm{C}_{3} \mathrm{~N}_{4}$ are photoexcited to generate $\mathrm{CB}$ electrons and $\mathrm{VB}$ holes. The internal electric field drives the electron migration from the $\mathrm{g}-\mathrm{C}_{3} \mathrm{~N}_{4} \mathrm{CB}$ to the $\mathrm{Bi}_{4} \mathrm{Ti}_{3} \mathrm{O}_{12} \mathrm{CB}$ and conversely the hole migration from the $\mathrm{Bi}_{4} \mathrm{Ti}_{3} \mathrm{O}_{12} \mathrm{VB}$ to the $\mathrm{g}-\mathrm{C}_{3} \mathrm{~N}_{4} \mathrm{VB}$ by using Au nanoparticles as the "bridge". Consequently it results in the efficient separation of the photoproduced electrons and holes, which is confirmed by the photocurrent and photoelectrochemical impedance spectroscopy (EIS) analyses (Fig. S1 and S2). As a result, more electrons accumulated in the $\mathrm{CB}$ of $\mathrm{Bi}_{4} \mathrm{Ti}_{3} \mathrm{O}_{12}$ and holes accumulated in the $\mathrm{VB}$ of $\mathrm{g}-\mathrm{C}_{3} \mathrm{~N}_{4}$ are expected to participate in the photoreactions. This is the major factor resulting in the enhanced photocatalysis capacities of the ternary CN@Au@BTO heterojunction composite photocatalysts. Moreover, other secondary factors could also cause the dye degradation. For example, the LSPR of Au nanoparticles could cause the local electromagnetic field enhancement and thus stimulate the production of additional electrons/holes in $\mathrm{Bi}_{4} \mathrm{Ti}_{3} \mathrm{O}_{12}$ and g- $\mathrm{C}_{3} \mathrm{~N}_{4}$, and the LSPR-induced electrons in $\mathrm{Au}$ nanoparticles could also take part in the photoreactions.

As the main reactive species confirmed in the $\mathrm{CN} @ A u @ B T O$ photocatalytic system, $\cdot \mathrm{O}_{2}{ }^{-}$radicals can be thermodynamically generated via the reaction between the $\mathrm{CB}$ electrons in $\mathrm{Bi}_{4} \mathrm{Ti}_{3} \mathrm{O}_{12}$ with adsorbed $\mathrm{O}_{2}$ species since the $\mathrm{Bi}_{4} \mathrm{Ti}_{3} \mathrm{O}_{12} \mathrm{CB}$ potential $\left(-0.19 \mathrm{~V}\right.$ vs $\mathrm{NHE}$ ) is negative to the $\mathrm{O}_{2} / \cdot \mathrm{O}_{2}{ }^{-}$redox potential ($0.13 \mathrm{~V}$ vs NHE [66]). From the thermodynamic viewpoint, the holes in theg- $\mathrm{C}_{3} \mathrm{~N}_{4} \mathrm{VB}$ cannot combine with $\mathrm{OH}^{-}$or $\mathrm{H}_{2} \mathrm{O}$ species to form $\cdot \mathrm{OH}$ radicals, because the $\mathrm{g}-\mathrm{C}_{3} \mathrm{~N}_{4} \mathrm{VB}$ potential $(+1.64 \mathrm{~V}$ vs $\mathrm{NHE})$ is not sufficiently positive when compared with $\mathrm{E}^{0}\left(\mathrm{OH}^{-} / \cdot \mathrm{OH}\right)=+1.99 \mathrm{~V}$ and $\mathrm{E}^{\mathrm{O}}\left(\mathrm{H}_{2} \mathrm{O} / \cdot \mathrm{OH}\right)=+2.38 \mathrm{~V}$ vs $\mathrm{NHE}[66]$. 
Direct oxidation by the photoexcited $\mathrm{h}^{+}$is suggested to be another important mechanism causing the dye degradation, which agrees with the active species trapping experiment results.

\section{Conclusions}

By coupling $\mathrm{Bi}_{4} \mathrm{Ti}_{3} \mathrm{O}_{12}$ and $\mathrm{g}-\mathrm{C}_{3} \mathrm{~N}_{4}$ nanosheets face-to-face and sandwiching Au nanoparticles between them, 2D/OD/2D face-to-face contact g- $\mathrm{C}_{3} \mathrm{~N}_{4} @ A u @ \mathrm{Bi}_{4} \mathrm{Ti}_{3} \mathrm{O}_{12}$ heterojunction photocatalysts have been prepared. Photocatalytic experiments suggest a good activity of the as-prepared ternary composite photocatalysts for photocatalytically degrading RhB under simulated sunlight irradiation. At 120 min of photoreaction, the 10\%CN@4.2\%Au@BTO composite photocatalyst is demonstrated to photocatalyze $94.4 \%$ degradation of $\mathrm{RhB}$. Its photodegradation activity is determined by the degradation kinetic analysis to be about 2.3 and 5.0 times larger than that of bare $\mathrm{Bi}_{4} \mathrm{Ti}_{3} \mathrm{O}_{12}$ and g- $\mathrm{C}_{3} \mathrm{~N}_{4}$ nanosheets, respectively. The enhanced photodegradation mechanism of the ternary composite photocatalysts is dominantly attributed to the photoexcited electron/hole transfer between $\mathrm{Bi}_{4} \mathrm{Ti}_{3} \mathrm{O}_{12}$ and g- $\mathrm{C}_{3} \mathrm{~N}_{4}$ nanosheets and efficient spatial separation of the electron/hole pairs. The role of Au nanoparticles sandwiched between $\mathrm{Bi}_{4} \mathrm{Ti}_{3} \mathrm{O}_{12}$ and g- $\mathrm{C}_{3} \mathrm{~N}_{4}$ nanosheets is to act as the "bridge" to facilitate the carrier transfer.

\section{Abbreviations}

RhB: rhodamine B; CB: conduction band; VB: valence band; $\mathrm{e}^{-}$: electrons; $\mathrm{h}^{+}$: holes; LSPR: localized surface plasmon resonance; $\mathrm{BTO}: \mathrm{Bi}_{4} \mathrm{Ti}_{3} \mathrm{O}_{12} ; 2 \mathrm{D}$ : two-dimensional; $\mathrm{CN}$ : g- $\mathrm{C}_{3} \mathrm{~N}_{4} ; \mathrm{XRD}$ : X-ray powder diffraction; u UV-vis DRS: Itraviolet-visible diffuse reflectance spectroscopy: FTIR: Fourier transform infrared; SEM: scanning electron microscopy; TEM: Transmission electron microscopy; XPS: X-ray photoelectron spectroscopy; SAED: selected area electron diffraction; HRTEM: high-resolution scanning electron microscopy; EDS: Energy-dispersive X-ray spectroscopy; DF-STEM: dark-field scanning transmission electron microscopy; $\bullet \mathrm{OH}$ : hydroxyl; $\cdot \mathrm{O}_{2}{ }^{-}$: superoxide; $\mathrm{BQ}$ : benzoquinone; $\mathrm{AO}$ : ammonium oxalate

\section{Declarations}

Acknowledgments: This work was supported by the National Natural Science Foundation of China (Grant No. 51662027) and the HongLiu First-Class Disciplines Development Program of Lanzhou University of Technology.

Author Contributions: H.Y. conceived the idea of experiment; H.G., X.Z. and H.Z. performed the experiments; H.G., X.Z., H.Z., J.C., S.W. and H.Y. discussed the results; H.Y. wrote the manuscript; J.C. improved the English language; All authors read and approved the final manuscript.

Conflicts of Interest: The authors declare that they have no competing interests. 


\section{References}

1. Yan $Y X$, Yang $H, Y i Z$, Xian $T$ (2019) $\mathrm{NaBH}_{4}$-reduction induced evolution of Bi nanoparticles from BiOCl nanoplates and construction of promising Bi@BiOCl hybrid photocatalysts. Catalysts 9:795

2. Wang S, Chen C, Li Y, Zhang Q, Li Y, Gao H (2019) Synergistic effects of optical and photoluminescence properties, charge transfer, and photocatalytic activity in $\mathrm{MgAl}_{2} \mathrm{O}_{4}$ : $\mathrm{Ce}$ and $\mathrm{Mn}$-Co doped $\mathrm{MgAl}_{2} \mathrm{O}_{4}$ :Ce phosphors. J Electron Mater 48:6675-6685

3. He ZM, Tang B, Su JB, Xia YM (2018) Fabrication of novel $\mathrm{Cu}_{2} \mathrm{O} / \mathrm{Bi}_{24} \mathrm{O}_{31} \mathrm{Br}_{10}$ composites and excellent photocatalytic performance. J Mater Sci-Mater El 29:19544-19553

4. Sushma, Kumari M, Saroha AK (2018) Performance of various catalysts on treatment of refractory pollutants in industrial wastewater by catalytic wet air oxidation: A review. J Environ Manage 228:169-188

5. Yan YX, Yang H, Yi Z, Xian T, Li RS, Wang XX (2019) Construction of $\mathrm{Ag}_{2} \mathrm{~S} @ \mathrm{CaTiO}{ }_{3}$ heterojunction photocatalysts for enhanced photocatalytic degradation of dyes. Desalin Water Treat 170:349-360

6. Wang SF, Gao HJ, Wei Y, Li YW, Yang XH, Fang LM, Lei L (2019) Insight into the optical, color, photoluminescence properties, and photocatalytic activity of the $\mathrm{N}-\mathrm{O}$ and $\mathrm{C}-\mathrm{O}$ functional groups decorating spinel type magnesium aluminate. CrystEngComm 21:263-277

7. Yi Z, Li X, Wu H, Chen XF, Yang H, Tang YJ, Yi YG, Wang JQ, Wu PH (2019) Fabrication of $\mathrm{ZnO@Ag} \mathrm{PO}_{4}$ core-shell nanocomposite arrays as photoanodes and their photoelectric properties. Nanomaterials 9:1254

8. Xia YM, He ZM, Hu KJ, Tang B, Su JB, Liu Y, Li XP (2018) Fabrication of n-SrTiO ${ }_{3} / \mathrm{p}-\mathrm{Cu}_{2} \mathrm{O}$ heterojunction composites with enhanced photocatalytic performance. J Alloy Compd 753:356-363

9. Wang SY, Yang H, Yi Z, Wang XX (2019) Enhanced photocatalytic performance by hybridization of $\mathrm{Bi}_{2} \mathrm{WO}_{6}$ nanoparticles with honeycomb-like porous carbon skeleton. J Environ Manage 248:109341

10. Ahmadi M, Motlagh HR, Jaafarzadeh N, Mostoufi A, Saeedi R, Barzegar G, Jorfi S (2017) Enhanced photocatalytic degradation of tetracycline and real pharmaceutical wastewater using $\mathrm{MWCNT/ \textrm {TiO } _ { 2 }}$ nano-composite. J Environ Manage 186:55-63

11. Cai C, Han SB, Liu W, Sun K, Qiao L, Li S, Zu XT (2020) Tuning catalytic performance by controlling reconstruction process in operando condition. Appl Catal B-Environ 260:118103

12. Pang ZY, Tong H, Wu XX, Zhu JK, Wang XX, Yang H, Qi YP (2018) Theoretical study of multiexposure zeroth-order waveguide mode interference lithography. Opt Quant Electron 50:335

13. Tong H, Xu YQ, Su YW, Wang XX (2019) Theoretical study for fabricating elliptical subwavelength nanohole arrays by higher-order waveguide-mode interference. Results Phys 14:102460

14. Wang XX, Pang ZY, Yang H, Qi YP (2019) Theoretical study of subwavelength circular grating fabrication based on continuously exposed surface plasmon interference lithography. Results Phys 14:102446 
15. Cen CL, Chen ZQ, Xu DY, Jiang LY, Chen XF, Yi Z, Wu PH, Li GF, Yi YG (2020) High quality factor, high sensitivity metamaterial graphene-perfect absorber based on critical coupling theory and impedance matching. Nanomaterials 10:95

16. Cen CL, Zhang YB, Chen XF, Yang H, Yi Z, Yao WT, Tang YJ, Yi YG, Wang JQ, Wu PH (2020) A dualband metamaterial absorber for graphene surface plasmon resonance at terahertz frequency. Physica E 117:113840

17. Li DJ, Zu XT, Ao DY, Tang QB, Fu YQ, Guo YJ, Bilawal K, Bilal Faheem M, Li L, Li S, Tang YL (2019) High humidity enhanced surface acoustic wave (SAW) $\mathrm{H}_{2} \mathrm{~S}$ sensors based on sol-gel CuO films. Sensor Actuat B-Chem 294:55-61

18. Li J.K, Chen ZQ, Yang H, Yi Z, Chen XF, Yao WT, Duan T, Wu PH, Li GF, Yi YG (2020) Tunable broadband solar energy absorber based on monolayer transition metal dichalcogenides materials using Au nanocubes. Nanomaterials 10:257

19. Han SB, Zhu YM, Cai C, Zhu JK, Han WB, Chen L, Zu XT, Yang H, Gu M (2019) Failure mechanism of $\mathrm{Au} @ \mathrm{Co}_{9} \mathrm{~S}_{8}$ yolk-shell anode in Li-ion batteries unveiled by in-situ transmission electron microscopy. Appl Phys Lett 114:113901

20. Zhao FA, Xiao HY, Bai XM, Zu XT (2019) Effects of Ag doping on the electronic and optical properties of CdSe quantum dots. Phys Chem Chem Phys 21:16108-16119

21. Wang YP, Yang H, Sun XF, Zhang HM, Xian T (2020) Preparation and photocatalytic application of ternary $\mathrm{n}-\mathrm{BaTiO}_{3} / \mathrm{Ag} / \mathrm{p}-\mathrm{AgBr}$ heterostructured photocatalysts for dye degradation. Mater Res Bull 124:110754

22. Esmaeili A, Entezari MH (2016) Sonosynthesis of an Ag/AgSr/Graphene-oxide nanocomposite as a solar photocatalyst for efficient degradation of methyl orange. J Colloid Interf Sci 466:227-237

23. Di LJ, Xian T, Sun XF, Li HQ, Zhou YJ, Ma J, Yang H (2019) Facile preparation of CNT/Ag 2 nanocomposites with improved visible and NIR light photocatalytic degradation activity and their catalytic mechanism. Micromachines 10:503

24. Karmaoui M, Lajaunie L, Tobaldi DM, Leonardi G, Benbayer C, Arenal R, Labrincha JA (2017) Modification of anatase using noble-metals ( $\mathrm{Au}, \mathrm{Pt}, \mathrm{Ag})$, Toward a nanoheterojunction exhibiting simultaneously photocatalytic activity and plasmonic gas sensing. Appl Catal B-Environ 218:370384

25. Xian T, Di LJ, Sun XF, Li HQ, Zhou YJ, Yang H (2019) Photo-Fenton degradation of A07 and photocatalytic reduction of $\mathrm{Cr}(\mathrm{VI})$ over $\mathrm{CQD}$-decorated $\mathrm{BiFeO}_{3}$ nanoparticles under visible and NIR light irradiation. Nanoscale Res Lett 14:397

26. Xian T, Sun XF, Di LJ, Zhou YJ, Ma J, Li HQ, Yang H (2019) Carbon quantum dots (CQDs) decorated $\mathrm{Bi}_{2} \mathrm{O}_{3-x}$ hybrid photocatalysts with promising NIR-light-driven photodegradation activity for A07. Catalysts 9:1031

27. Jonathan AS, Ai LK, Jennifer AD (2012) Quantum plasmon resonances of individual metallic nanoparticles. Nature 483:421-428 
28. Wang XX, Zhu JK, Wen XL, Wu XX, Wu Y, Su YW, Tong H, Qi YP, Yang H (2019) Wide range refractive index sensor based on a coupled structure of Au nanocubes and Au film. Opt Mater Express 9:30793088

29. Qin F, Chen ZQ, Chen XF, Yi Z, Yao WT, Duan T, Wu PH, Yang H, Li GF, Yi YG (2020) A tunable tripleband near-infrared metamaterial absorber based on Au nano-cuboids array. Nanomaterials 10:207

30. He ZM, Xia YM, Su JB (2018) Fabrication of novel AgBr/ $\mathrm{Bi}_{24} \mathrm{O}_{31} \mathrm{Br}_{10}$ composites with excellent photocatalytic performance. RSC Adv 8:39187-39196

31. Guan ST, Yang H, Sun XF, Xian T (2020) Preparation and promising application of novel $\mathrm{LaFeO}_{3} / \mathrm{BiOBr}$ heterojunction photocatalysts for photocatalytic and photo-Fenton removal of dyes. Opt Mater 100:109644

32. Kaur K, Badru R, Singh PP, Kaushal S (2020) Photodegradation of organic pollutants using heterojunctions: A review. J Environ Chem Eng 8:103666

33. Wang SY, Ma JY, Li ZJ, Su HQ, Alkurd NR, Zhou WL, Wang L, Du B, Tang YL, Ao DY, et al. (2015) Surface acoustic wave ammonia sensor based on $\mathrm{ZnO} / \mathrm{SiO}_{2}$ composite film. J Hazard Mater 285:368-374

34. Wu H, Jile H, Chen Z, Xu D, Yi Z, Chen X, Chen J, Yao W, Wu P, Yi Y (2020) Fabrication of Zn0@MoS nanocomposite heterojunction arrays and their photoelectric properties. Micromachines 11:189

35. Zhao XX, Yang H, Cui ZM, Yi Z, Yu H (2019) Synergistically enhanced photocatalytic performance of $\mathrm{Bi}_{4} \mathrm{Ti}_{3} \mathrm{O}_{12}$ nanosheets by $\mathrm{Au}$ and Ag nanoparticles. J Mater Sci-Mater El 30:13785-13796

36. Chen ZW, Jiang H, Jin WL, Shi CK (2016) Enhanced photocatalytic performance over $\mathrm{Bi}_{4} \mathrm{Ti}_{3} \mathrm{O}_{12}$ nanosheets with controllable size and exposed $\{001\}$ facets for Rhodamine $B$ degradation. Appl Catal B-Environ 180:698-706

37. Li ZA, Wang JL, Chen JF, Liu L, Yang XF, Chen T, Chen ZZ, Yang MM, Yan WS, Fu ZP, Liu M, Lu YL (2019) Realizing nitrogen doping in $\mathrm{Bi}_{4} \mathrm{Ti}_{3} \mathrm{O}_{12}$ via low temperature synthesis and its enhanced photocatalytic performance. J Alloy Compd 806:492-499.

38. Dutta DP, Tyagi AK (2016) Facile sonochemical synthesis of Ag modified $\mathrm{Bi}_{4} \mathrm{Ti}_{3} \mathrm{O}_{12}$ nanoparticles with enhanced photocatalytic activity under visible light. Mater Res Bull 74:397-407

39. Odling G, Chatzisymeon E, Robertson N (2018) Sequential ionic layer adsorption and reaction (SILAR) deposition of $\mathrm{Bi}_{4} \mathrm{Ti}_{3} \mathrm{O}_{12}$ on $\mathrm{TiO}_{2}$ an enhanced and stable photocatalytic system for water purification. Catal Sci Technol 8:829-839

40. Zheng CX, Yang H, Cui ZM, Zhang HM, Wang XX (2017) A novel $\mathrm{Bi}_{4} \mathrm{Ti}_{3} \mathrm{O}_{12} / \mathrm{Ag}_{3} \mathrm{PO}_{4}$ heterojunction photocatalyst with enhanced photocatalytic performance. Nanoscale Res Lett 12:608

41. Das K, Majhi D, Bhoi YP, Mishra BG (2019) Combustion synthesis, characterization and photocatalytic application of $\mathrm{CuS} / \mathrm{Bi}_{4} \mathrm{Ti}_{3} \mathrm{O}_{12}$ p-n heterojunction materials towards efficient degradation of 2-methyl-4-chlorophenoxyacetic acid herbicide under visible light. Chem Eng $\mathrm{J}$ 362:588-599 
42. Cummins SE, Cross LE (1968) Electrical and optical properties of ferroelectric $\mathrm{Bi}_{4} \mathrm{Ti}_{3} \mathrm{O}_{12}$ single crystals. J Appl Phys 39:2268

43. Wang X, Maeda K, Thomas A, Takanabe K, Xin G, Carlsson JM, Domen K, Antonietti M (2009) A metal-free polymeric photocatalyst for hydrogen production from water under visible light. Nat Mater 8:76-80

44. Guo Y, Li JH, Gao ZQ, Zhu X, Liu Y, Wei ZB, Zhao W, Sun C (2016) A simple and effective method for fabricating novel $p-n$ heterojunction photocatalyst $g-C_{3} N_{4} / B_{4} T_{3} O_{12}$ and its photocatalytic performances. Appl Catal B-Environ 192:57-71

45. Di LJ, Yang H, Xian T, Chen XJ (2018) Construction of Z-scheme g- $\mathrm{C}_{3} \mathrm{~N}_{4} / \mathrm{CNT} / \mathrm{Bi}_{2} \mathrm{Fe}_{4} \mathrm{O}_{9}$ composites with improved simulated-sunlight photocatalytic activity for the dye degradation. Micromachines 9:613

46. Mohini R, Lakshminarasimhan N (2016) Coupled semiconductor nanocomposite g- $\mathrm{C}_{3} \mathrm{~N}_{4} / \mathrm{TiO}_{2}$ with enhanced visible light photocatalytic activity. Mater Res Bull 76:370-375

47. Yan YX, Yang H, Yi Z, Li RS, Xian T (2020) Design of ternary CaTiO ${ }_{3} / g-\mathrm{C}_{3} \mathrm{~N}_{4} / \mathrm{AgBr} Z$-scheme heterostructured photocatalysts and their application for dye photodegradation. Solid State Sci 100:106102

48. Wang YY, Chen ZQ, Xu DY, Yi Z, Chen XF, Chen J, Tang YJ, Wu PH, Li GF, Yi YG (2020) Triple-band perfect metamaterial absorber with good operating angle polarization tolerance based on split ring arrays. Results Phys 16:102951

49. Li DJ, Tang YL, Ao DY, Xiang X, Wang SY, Zu XT (2019) Ultra-highly sensitive and selective $\mathrm{H}_{2} \mathrm{~S}$ gas sensor based on CuO with sub-ppb detection limit. Int J Hydrogen Energ 44:3985-3992

50. Chen J, Wang XX, Tang F, Ye X, Yang LM, Zhang YB (2020) Substrates for surface-enhanced raman spectroscopy based on TiN plasmonic antennas and waveguide platforms. Results Phys 16:102867

51. Yan YX, Yang H, Yi Z, Xian T, Wang XX (2019) Direct Z-scheme CaTiO ${ }_{3} @ B i O B r$ composite photocatalysts with enhanced photodegradation of dyes. Environ Sci Pollut Res 26:29020-29031

52. Utara S, Hunpratub S (2018) Ultrasonic assisted synthesis of $\mathrm{BaTiO}_{3}$ nanoparticles at $25^{\circ} \mathrm{C}$ and atmospheric pressure. Ultrason Sonochem 41:441-448

53. Wang S, Gao H, Wang Y, Sun G, Zhao X, Liu H, Chen C, Yang L (2020) Effect of the sintering process on the structure colorimetric optical and photoluminescence properties of $\mathrm{SrWO}_{4}$ phosphor powders. J Electron Mater https://xs.scihub.Itd/https://doi.org/10.1007/s11664-020-07941-1

54. Wang S, Gao H, Chen C, Li Q, Li C, Wei Y, Fang L (2019) Effect of phase transition on optical and photoluminescence properties of nano- $\mathrm{MgWO}_{4}$ phosphor prepared by a gamma-ray irradiation assisted polyacrylamide gel method. J Mater Sci-Mater El 30:15744-15753

55. Dehghani Dastjerdi O, Shokrollahi $\mathrm{H}$, Yang H (2020) The enhancement of the Ce-solubility limit and saturation magnetization in the $\mathrm{Ce}_{0.25} \mathrm{Bi}_{\mathrm{x}} \mathrm{Pr}_{\mathrm{y}} \mathrm{Y}_{2.75-\mathrm{x}-\mathrm{y}} \mathrm{Fe}_{5} \mathrm{O}_{12}$ garnet synthesized by the conventional ceramic method. Ceram Int 46:2709-2723 
56. Yi Z, Zeng Y, Wu H, Chen XF, Fan YX, Yang H, Tang YJ, Yi YG, Wang JQ, Wu PH (2019) Synthesis, surface properties, crystal structure and dye-sensitized solar cell performance of $\mathrm{TiO}_{2}$ nanotube arrays anodized under different parameters. Results Phys 15:102609

57. Golkari M, Shokrollahi H, Yang H (2020) The influence of Eu cations on improving the magnetic properties and promoting the Ce solubility in the Eu, Ce-substituted garnet synthesized by the solid state route. Ceram Int (https://doi.org/10.1016/j.ceramint.2019.12.085).

58. Wang S, Gao H, Sun G, Li Y, Wang Y, Liu H, Chen C, Yang L (2020) Structure characterization, optical and photoluminescence properties of scheelite-type $\mathrm{CaWO}_{4}$ nanophosphors: Effects of calcination temperature and carbon skeleton. Opt Mater 99:109562

59. Gao HJ, Zheng CX, Yang H, Niu XW, Wang SF (2019) Construction of a CQDs/ $/ \mathrm{Ag}_{3} \mathrm{PO}_{4} / \mathrm{BiPO}_{4}$ heterostructure photocatalyst with enhanced photocatalytic degradation of rhodamine $\mathrm{B}$ under simulated solar irradiation. Micromachines 10:557

60. Barbero N, Vione D (2016) Why dyes should not be used to test the photocatalytic activity of semiconductor oxides. Environ Sci Technol 50:2130-2131

61. Xia YM, He ZM, Lu YL, Tang B, Sun SP, Su JB, Li XP (2018) Fabrication and photocatalytic property of magnetic $\mathrm{SrTiO}_{3} / \mathrm{NiFe}_{2} \mathrm{O}_{4}$ heterojunction nanocomposites. RSC Adv 8:5441-5450

62. Ye YC, Yang $\mathrm{H}$, Zhang $\mathrm{HM}$, Jiang $\mathrm{JL}$ (2018) A promising $\mathrm{Ag}_{2} \mathrm{CrO}_{4} / \mathrm{LaFeO}_{3}$ heterojunction photocatalyst applied to photo-Fenton degradation of RhB. Environ. Technol. (https //doi.org/10.1080/09593330.2018.1538261).

63. Rivas J, Solis RR, Gimeno O, Sagasti J (2015) Photocatalytic elimination of aqueous 2-methyl-4chlorophenoxyacetic acid in the presence of commercial and nitrogen-doped $\mathrm{TiO}_{2}$. Int $\mathrm{J}$ Environ $\mathrm{Sci}$ Technol 12:513-526

64. Wang S, Gao H, Chen C, Wei Y, Zhao X (2019) Irradiation assisted polyacrylamide gel route for the synthesize of the $\mathrm{Mg}_{1-x} \mathrm{Co}_{x} \mathrm{Al}_{2} \mathrm{O}_{4}$ nano-photocatalysts and its optical and photocatalytic performances. J Sol-Gel Sci Technol 92:186-199

65. Andersen T, Haugen HK, Hotop H (1999) Binding energies in atomic negative ions, III. J Phys Chem Ref Data 28:1511-1533

66. Wang YP, Jiang FC, Chen JF, Sun XF, Xian T, Yang H (2020) In situ construction of CNT/CuS hybrids and their application in photodegradation for removing organic dyes. Nanomaterials 10:178

67. Yan YX, Yang H, Yi Z, Wang XX, Li RS, Xian T (2020) Evolution of Bi nanowires from BiOBr nanoplates through a $\mathrm{NaBH}_{4}$ reduction method with enhanced photodegradation performance. Environ Eng Sci 37:64-77

\section{Figures}




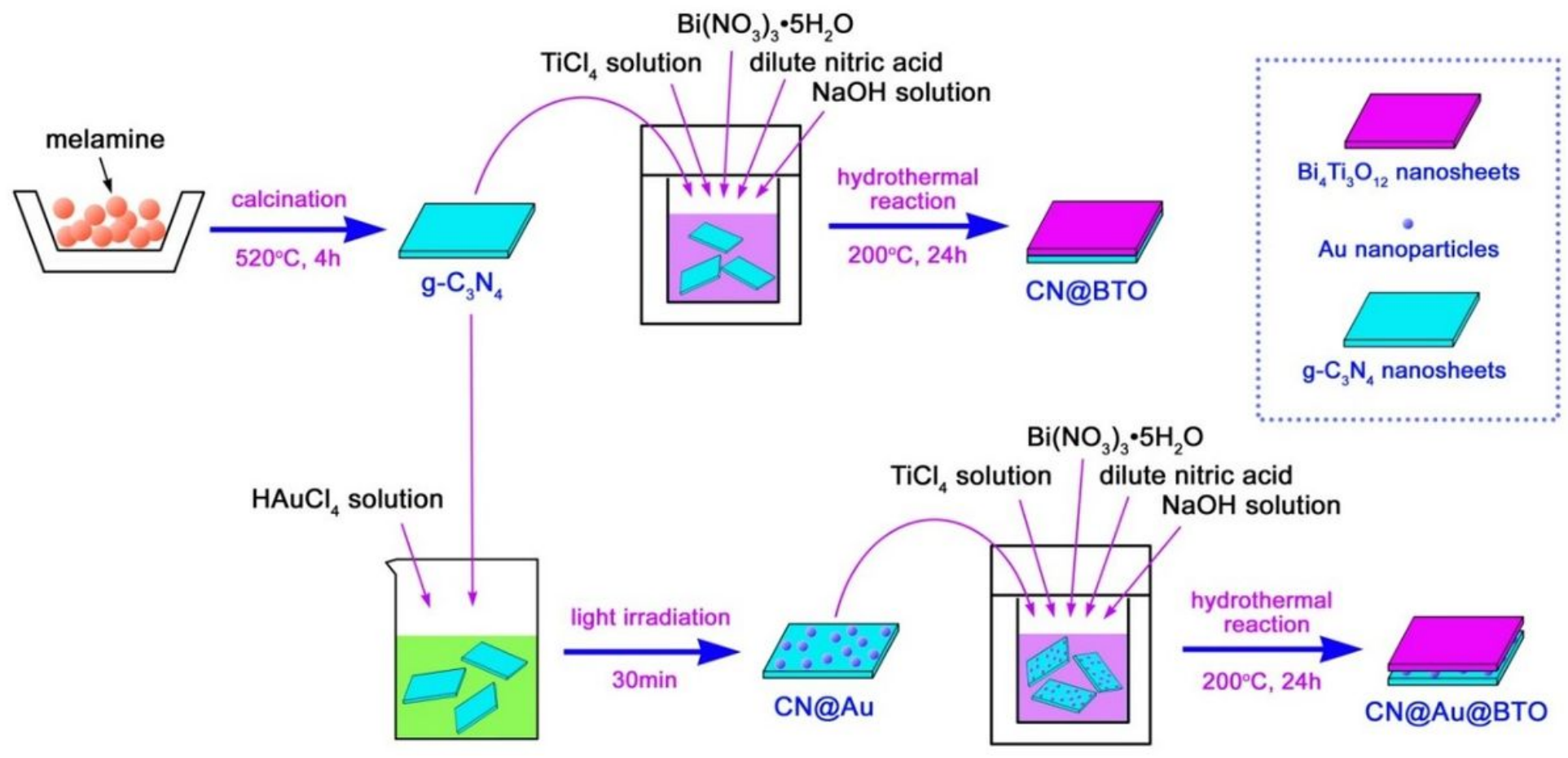

Figure 1

Schematic illustration of the preparation process of CN@BTO and CN@Au@BTO composite photocatalysts. 


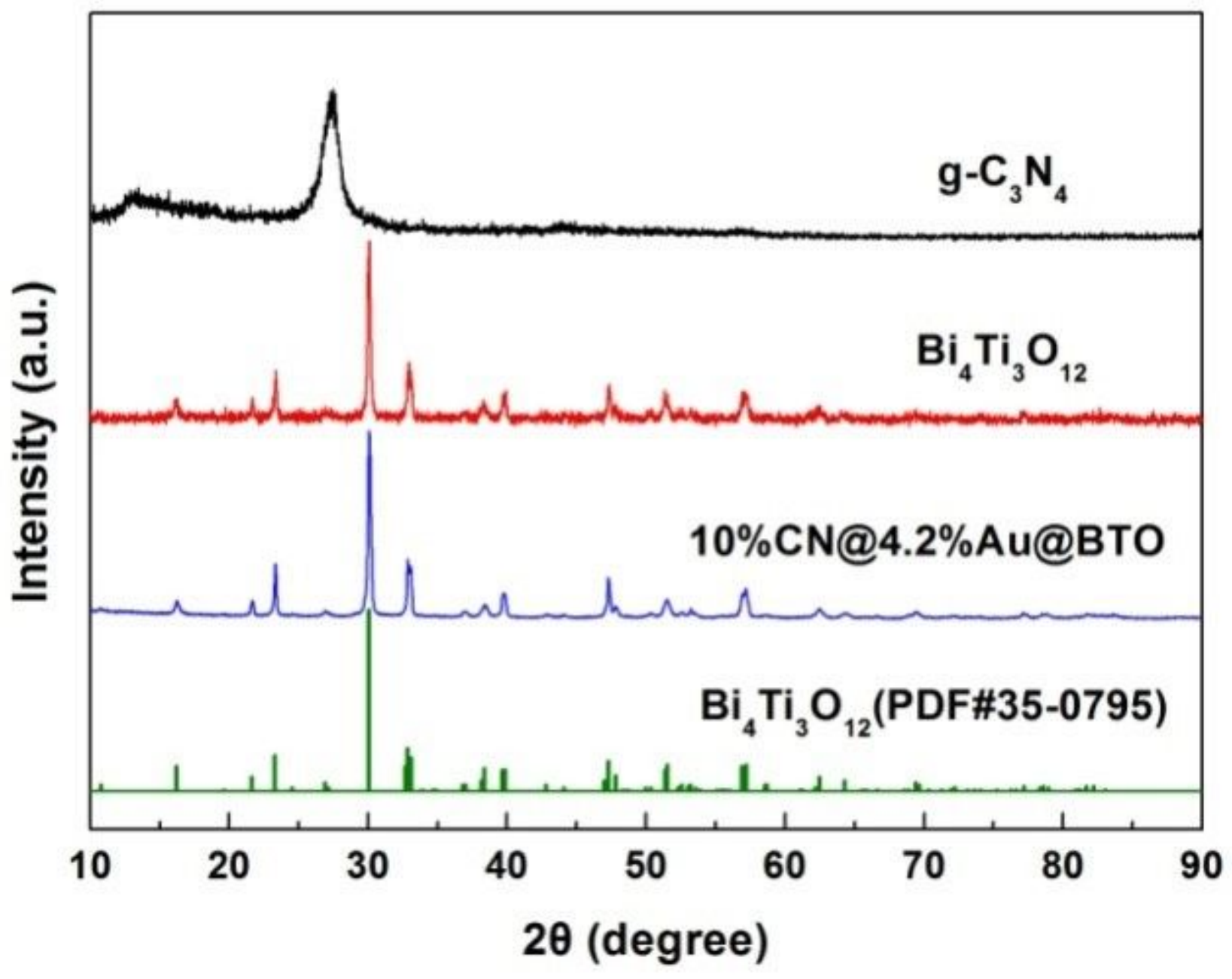

Figure 2

XRD patterns of g-C3N4, Bi4Ti3012 and 10\%CN@4.2\%Au@BTO. 

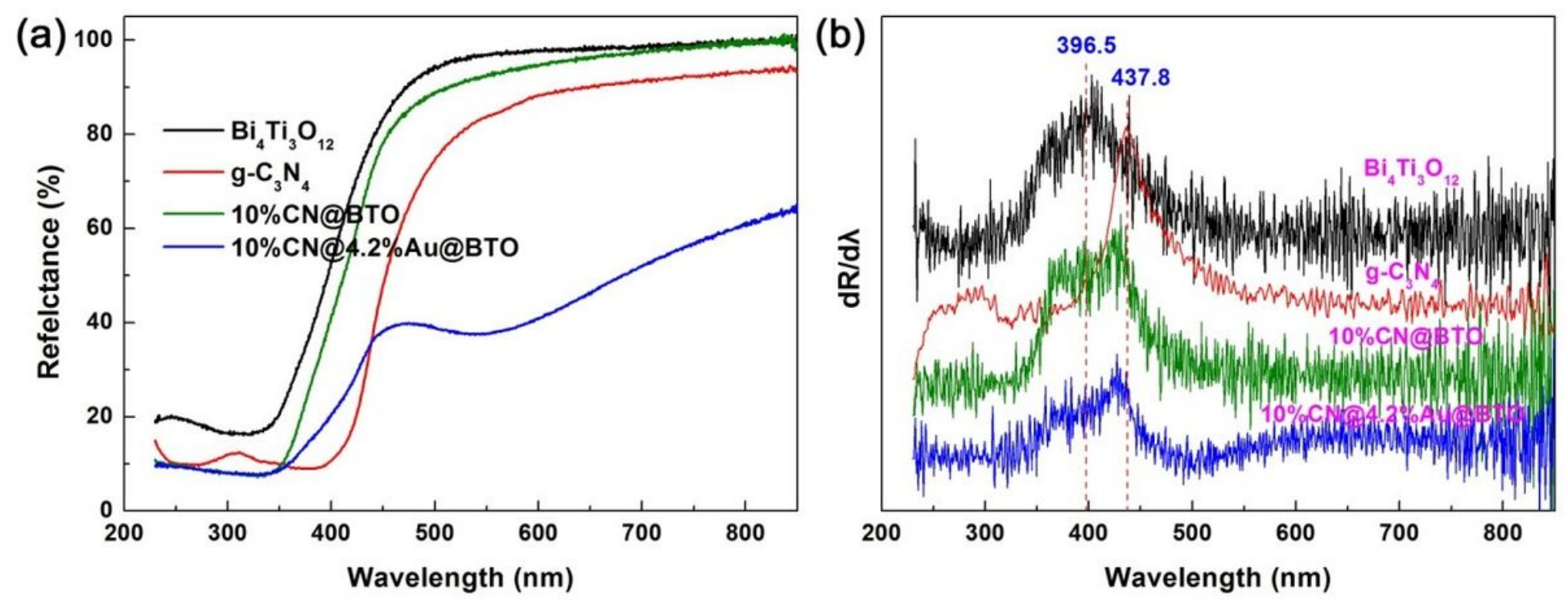

(c)

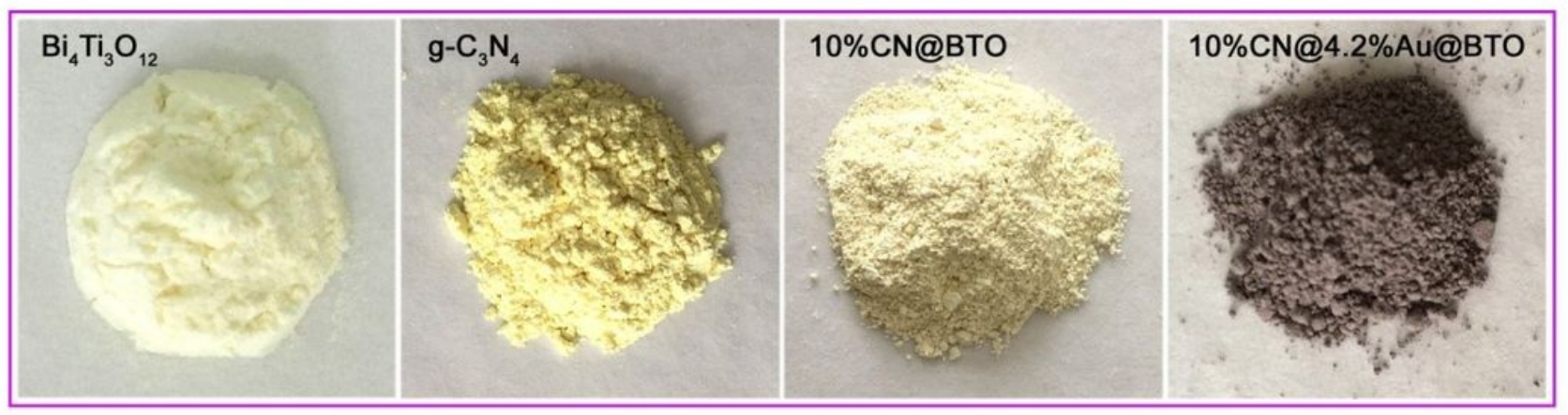

Figure 3

UV-vis DRS spectra (a), differential curves of the DRS spectra (b) and apparent colors (c) of Bi4Ti3012, gC3N4,10\%CN@BTO and 10\%CN@4.2\%Au@BTO. 

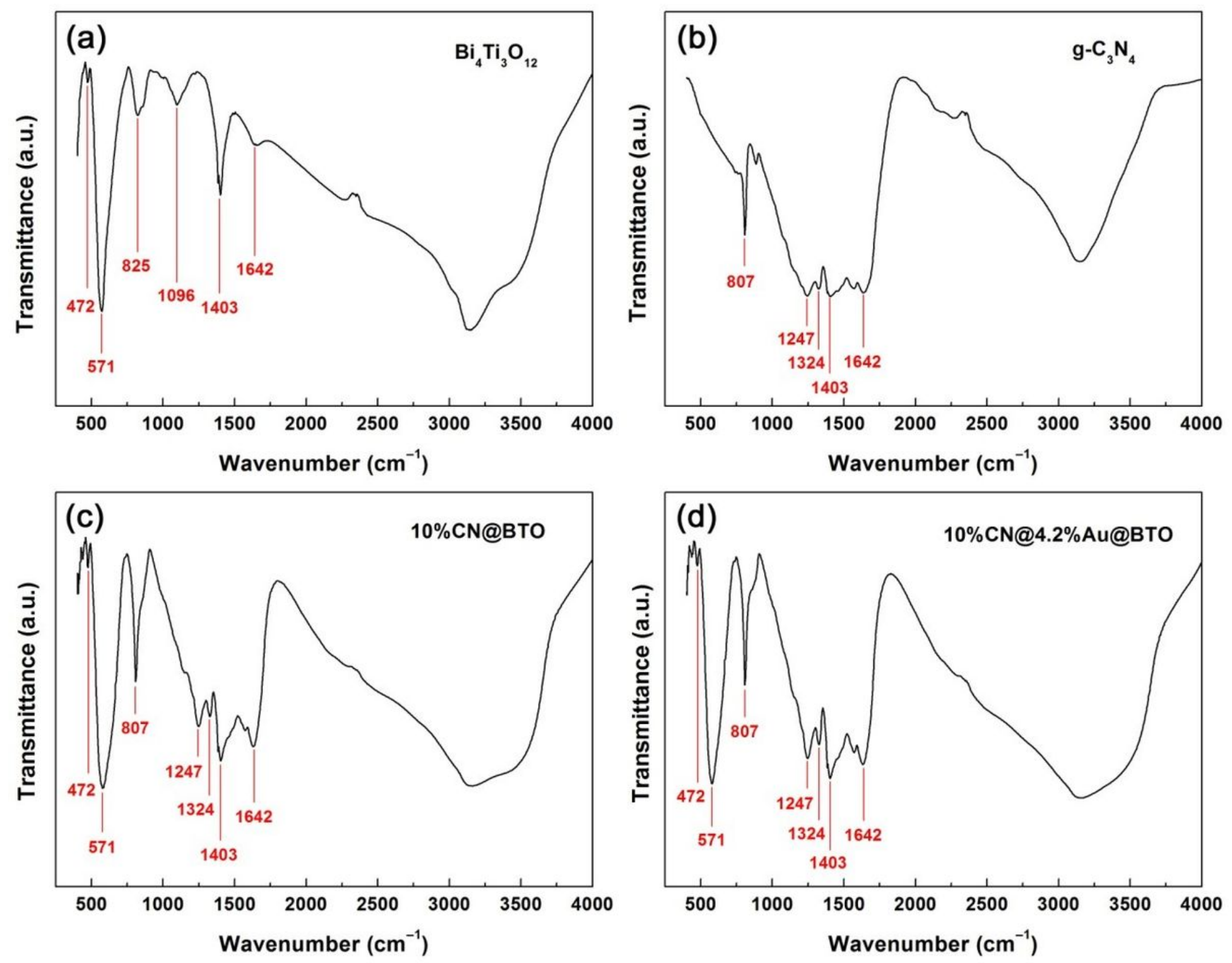

Figure 4

FTIR spectra of Bi4Ti3012 (a), g-C3N4 (b), 10\%CN@BTO (c) and 10\%CN@4.2\%Au@BTO (d). 


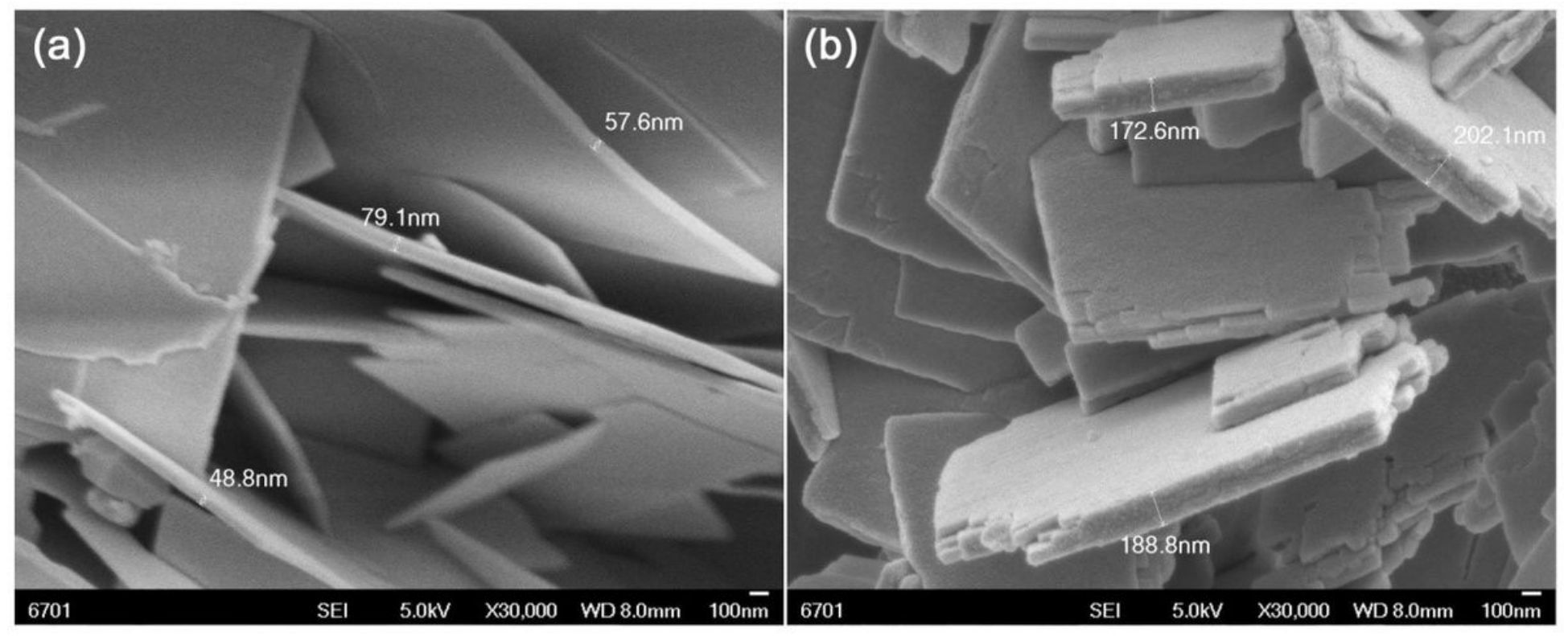

\section{Figure 5}

SEM images of (a) Bi4Ti3012 and (b) 10\%CN@4.2\%Au@BTO.

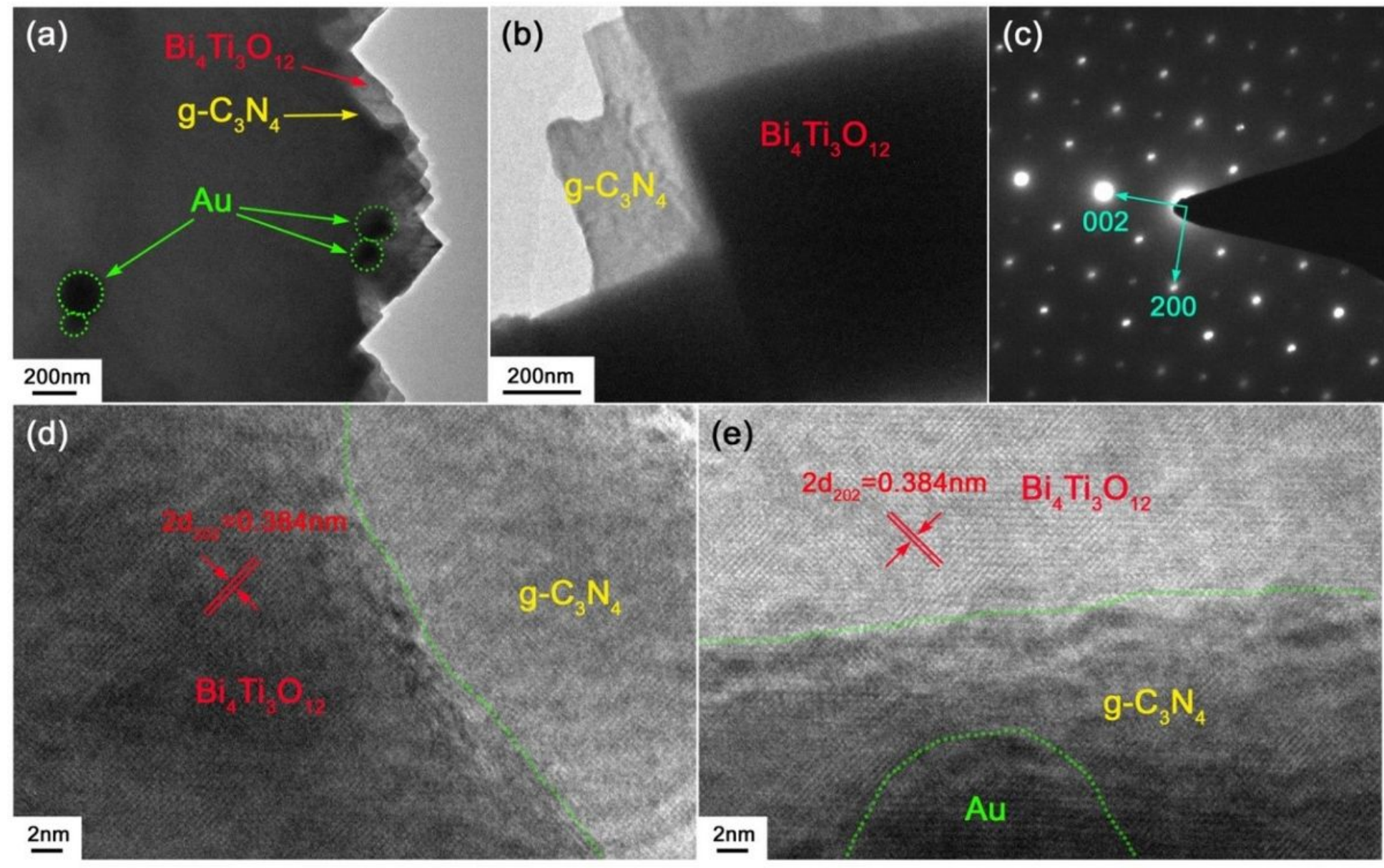

\section{Figure 6}

TEM images $(a, b)$, SAED pattern (c) and HRTEM images (d,e) of 10\%CN@4.2\%Au@BTO. 

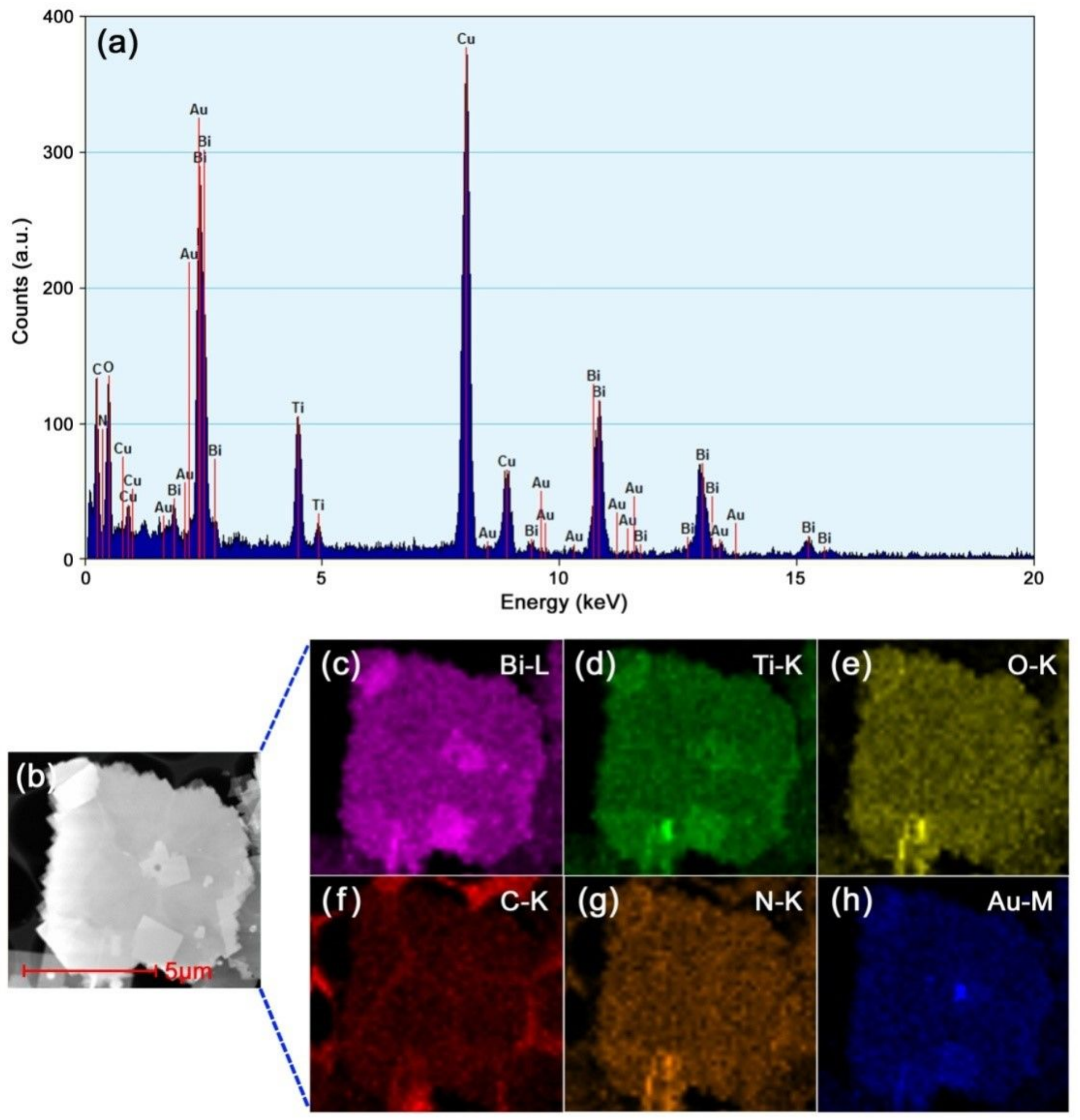

Figure 7

EDS spectrum (a), DF-STEM image (b) and EDS elemental mapping images (c-h) of 10\%CN@4.2\%Au@BTO. 

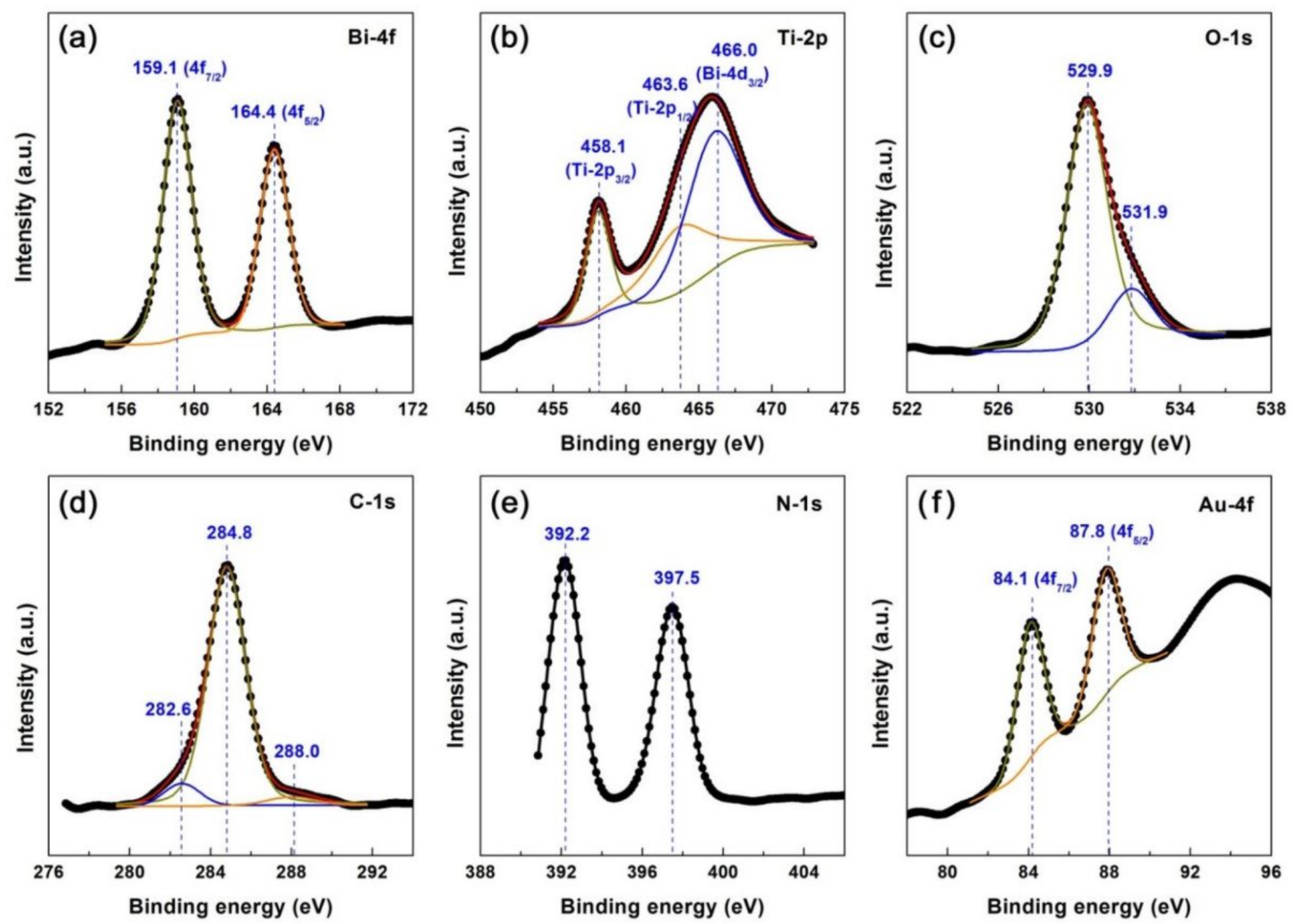

Figure 8

High-resolution XPS spectra of (a) Bi-4f, (b) Ti-2p, (c) 0-1s, (d) C-1s, (e) N-1s and (f) Au-4f of 10\%CN@4.2\%Au@BTO. 

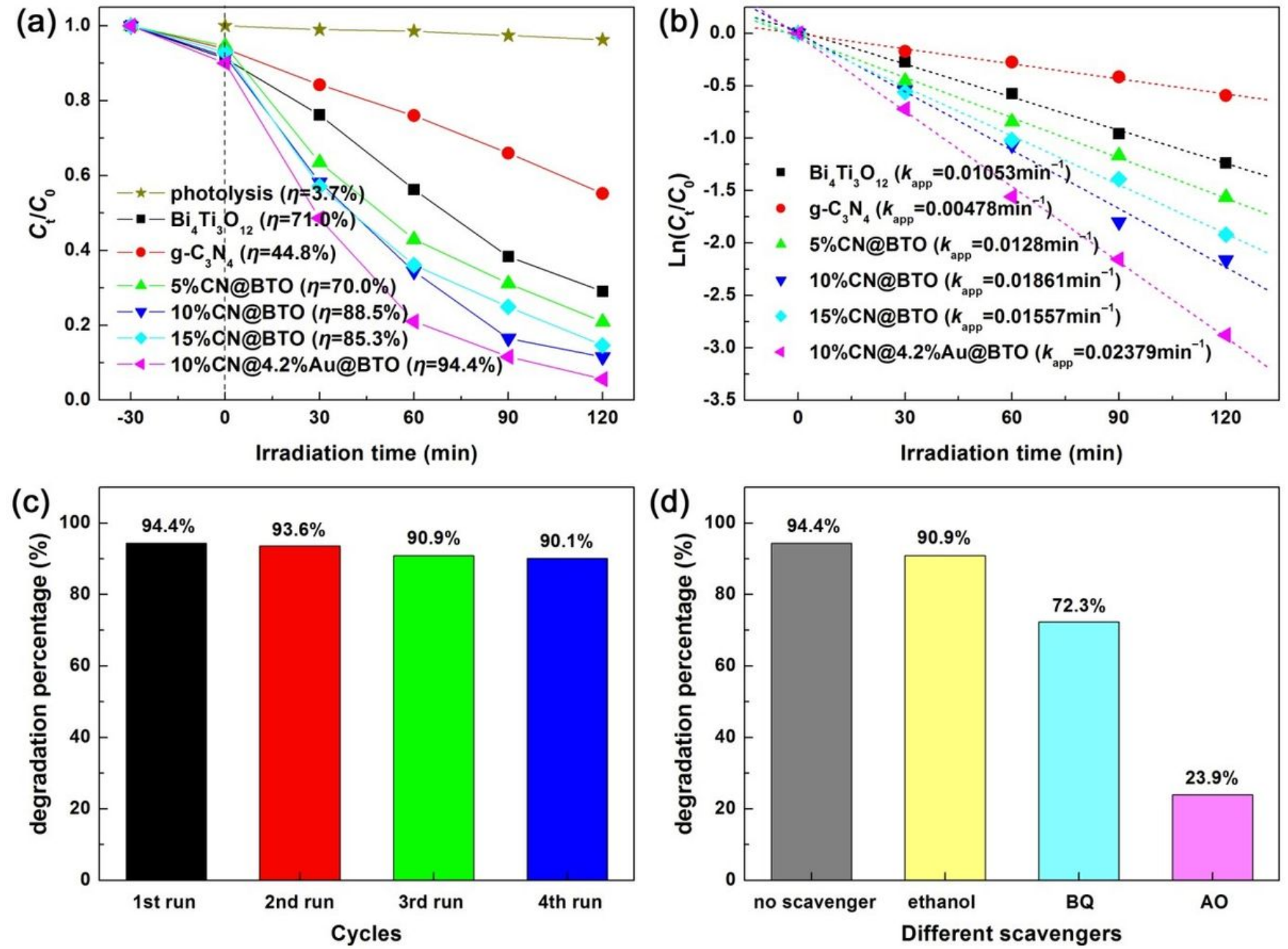

Figure 9

(a) Photodegradation plots of RhB photocatalyzed by all the samples. (b) RhB degradation kinetic plots.

(c) Photodegradation percentage of RhB over repeatedly used 10\%CN@4.2\%Au@BTO. (d) Effects of ethanol, BQ and AO on the RhB degradation percentage over 10\%CN@4.2\%Au@BTO. 


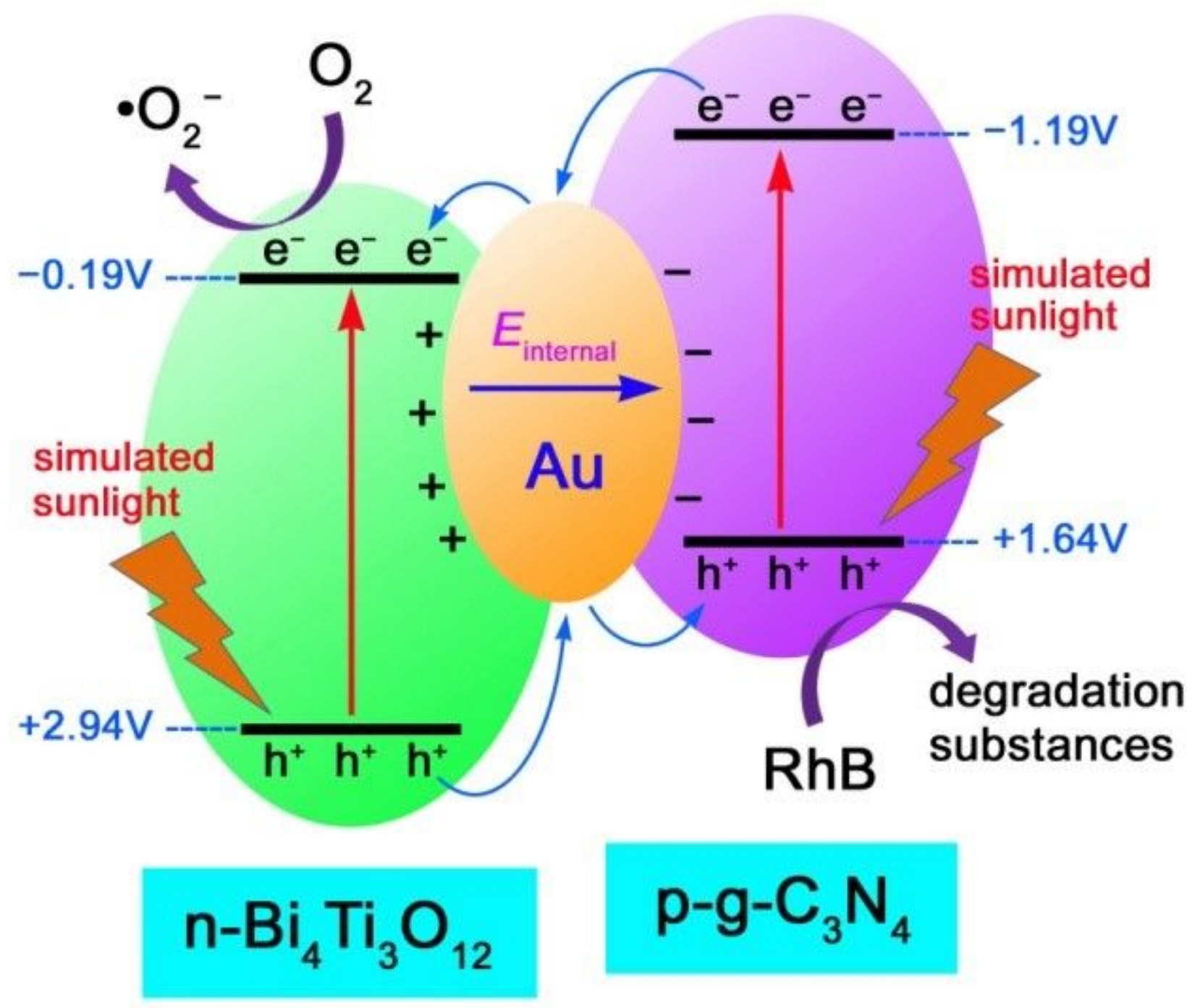

Figure 10

Schematic illustration of the photocatalytic mechanism of the g-C3N4@Au@Bi4Ti3012 heterojunction photocatalysts.

\section{Supplementary Files}

This is a list of supplementary files associated with this preprint. Click to download.

- SupportingInformation.docx 